\title{
The effects of losing sex on the molecular evolution of plant
}

\section{defense}

4 Diego Carmona, ${ }^{*, 1,2}$, Jesse D. Hollister, ${ }^{3}$ Stephan Greiner, ${ }^{4}$ Stephen I. Wright, ${ }^{5}$ Rob W. Ness, ${ }^{\dagger, 1}$

5 and Marc T.J. Johnson ${ }^{\dagger, 1}$

$6{ }^{1}$ Department of Biology, University of Toronto Mississauga, Mississauga, ON, Canada

$7 \quad{ }^{2}$ Departamento de Ecología Tropical, Campus de Ciencias Biológicas y Agropecuarias,

8 Universidad Autónoma de Yucatán, Mérida, Yucatán, México

$9 \quad{ }^{3}$ Stony Brook University, New York, United States

$10{ }^{4}$ Max Planck Institute of Molecular Plant Physiology, Potsdam-Golm, Germany

$11{ }^{5}$ Department of Ecology and Evolutionary Biology, University of Toronto, Toronto, ON,

12 Canada

${ }^{\dagger}$ These authors co-supervised the project.

15 *Corresponding author: diego.carmona@correo.uady.mx

16 Words

17 Abstract: 218

18 Introduction: 1019

19 Results: 1301

20 Discussion: 2636

21 Conclusions: 285

22 Methods: 2176

23 Citations: 151

24 Tables: 2

25 Figures: 4

26 Supplementary tables: $6+1$ xls file

27 Supplementary figures: 5

28 Characters

29 Total: 50820 


\section{Abstract}

It is hypothesized that the loss of sexual reproduction and reduced recombination rates decrease the ability for hosts to evolve in response to selection by parasites. Using transcriptomes from 32 species, we test whether repeated losses of sex in the plant genus Oenothera has resulted in changes to the evolution of defense genes against herbivores and pathogens. To achieve this, the function of 2,431 Oenothera orthologous genes was determined based on GO annotations from Arabidopsis thaliana. Phylogenetic Analysis by Maximum Likelihood (PAML) was then used to examine how the patterns of molecular evolution in 721 defense and 1,710 non-defense genes differ between sexual (16 spp.) and asexual (16 spp.) taxa. We test whether the relative rates of nonsynonymous to synonymous substitutions ( $\omega=d N / d S)$ in proteins with defensive function were higher in lineages with sexual reproduction $\left(\omega_{\text {sexual }}>\omega_{\mathrm{a}-}\right.$ sexual), and we asked if such patterns were exclusive for defense genes or not. We detected variability in the rate of amino acid replacements of proteins in $>50 \%$ of genes and positive selection on $3 \%$ of the genes examined. Nevertheless, our results clearly show that on average, signatures of positive and purifying selection on defense and non-defense genes are similar and only a small number of specific genes related to plant immune function may be affected by a loss of sex.

Running title: The effect of losing sex on plant defense

Key words: genome-wide analysis, genetic systems, synonymous and non-synonymous substitutions, fixation rates, permanent translocation heterozygosity 


\section{Introduction}

56 Plant species vary tremendously in their investment and efficacy of defenses against

57 herbivores and other plant parasites (Rosenthal and Janzen 1979; Karban and Baldwin 1997;

58 Carmona et al. 2011; Turcotte et al. 2014). Leading hypotheses to explain variation in the

59 evolution of plant defenses include tradeoffs between growth and defense (Herms and

60 Mattson 1992), the availability of resources within environments (Coley et al. 1985; Endara

61 and Coley 2011), the apparency of plants to herbivores (Feeny 1976; Turcotte et al. 2014;

62 Strauss et al. 2015), and variation in the coevolutionary history of plant-herbivore interactions

63 (Agrawal et al. 2009). These hypotheses have been unable to fully account for the micro- and

64 macroevolutionary patterns in defense traits, suggesting other explanations need

65 consideration. Recent evidence suggests that variation in plant reproductive systems, which

66 include obligate asexual reproduction, self-fertilization, obligate outcrossing, and various

67 combinations of these modes of reproduction, may be among the most important factors

68 shaping the evolution of defenses against plant parasites (Levin 1975; Campbell 2014; Carr

69 and Eubanks 2014; Johnson et al. 2015).

A rich body of theory describes how the suppression of sex is predicted to affect

71

72

evolution (Fisher 1930; Muller 1932; Felsenstein 1974; Hartfield and Keightley 2012; Lively and Morran 2014; Neiman et al. 2017). Through the effects of recombination and segregation, sex is predicted to increase the efficiency by which natural selection purges deleterious mutations (Muller 1964; Kondrashov 1988; Gabriel et al. 1993), and fixes beneficial alleles (Fisher 1930; Muller 1932). In the context of plant defenses, this theory supports the prediction that a loss of sex will negatively affect the evolution of plant defense, especially because an important advantage of sex is that it enables hosts to keep pace with their coevolving parasites (Levin 1975; Otto and Nuismer 2004; Salathé et al. 2008; Lively 2010; 
Neiman et al. 2017), such as those experienced by plant-parasite interactions (Ehrlich and Raven 1964; Busch et al. 2004). Indeed, plant defense genes are frequently highly polymorphic and show signatures of ongoing balancing selection (Tian et al 2002; Prasad et al. 2012). Nevertheless, there have been few tests of how a loss of sexual reproduction, through its effects on recombination and/or segregation of alleles, affects the evolution plant defense against herbivores and pathogens (Johnson et al. 2015).

Recent evidence suggests that increased selfing or a loss of sex affects the evolution of resistance against herbivores (Johnson et al. 2015). For example, Campbell and Kessler (2013) experimentally showed that self-compatible species exhibit a marginal reduction in constitutive defenses and a clear increase in inducible defenses compared to selfincompatible species. In the plant genus Oenothera (evening primrose, Onagraceae), multiple transitions to a functionally asexual genetic system called permanent translocation heterozygosity (PTH) is associated with the evolution of increased susceptibility to generalist herbivores (Johnson et al. 2009), which might be explained by a reduction in the diversity of flavonoid secondary metabolites (Johnson et al. 2014). These examples and others (Adler et al. 2012) highlight how reduced recombination (i.e., reduction on the effective population sizes; $\mathrm{Ne}$ ) due to inbreeding or a loss of sex can affect evolution of defense. Despite extensive work on the genetic basis and molecular evolution of plant defenses against parasites (Tian et al. 2002; Tiffin and Moeller 2006), the effects of sex on the evolution of defense genes are unclear (Gos et al. 2012; Sicard et al. 2015). Some of the best examples of how sex affects the molecular evolution of defense and non-defense genes again stems from work on Oenothera (but see Gos et al. 2012; Sicard et al. 2015). HerschGreen et al. (2012) found positive selection on a defense protein against fungal pathogens (basic chitinase, $c h i B$ ) in sexual but not in functionally asexual Oenothera. Moreover, Oenothera has been used to examine how a loss of sex affects genomic evolution more 
104

105

106

107

generally. Using a transcriptome dataset from 29 species of Oenothera, Hollister et al. (2015) showed that PTH lineages accumulate more deleterious mutations than non-PTH sexual lineages because of reduced selection efficacy. However, this study did not explicitly test for positive selection nor how these patterns might vary across genes with different gene functions, such as defense vs. non-defense genes.

Here, we test whether a loss of sexual reproduction in Oenothera affects the molecular evolution of defense and non-defense genes. Our study addresses the following research questions: 1) What is the distribution of positive and purifying selection across protein-coding genes in Oenothera? Estimating the proportion of genes that exhibit both positive and purifying selection provides the basis for understanding how the loss of sex may affect the molecular evolution of defense and non-defense proteins. 2) Are defense genes subject to weaker purifying selection and stronger positive selection than non-defense genes (fig. 1)? Greater variability in rates of amino acid replacements (i.e., heterogeneity) within defense compared to non-defense genes would be consistent with faster and less selectively constrained molecular evolution. Similarly, a greater frequency of positively selected amino acid sites would indicate that defense genes are subject to stronger and more frequent adaptive evolution than non-defense genes. 3) Does the strength and direction of selection in defense and non-defense genes vary with sexual system? We predict that sexual Oenothera species will exhibit stronger and more frequent positive selection than functionally asexual PTH species, and this effect will be stronger for defense genes. Similarly, we expect that purifying selection will be stronger on non-defense gene, and that PTH lineages will experience relaxed selection on these sites compared to sexual species, as shown by Hollister et al. (2015). 
FIG. 1. Predictions on molecular evolutionary interaction of defense vs. non-defensive genes with sexual and asexual reproduction. Here we expect that non-defensive genes are under strong purifying selection while defensive genes are expected to be under strong positive selection because of host-parasite coevoluton. Based on the theoretical expectation that the efficacy of natural selection will be reduced without sex, we expect a reduction in the magnitude of positive selection on defense genes in asexuals ( $\omega_{\text {Defense Sex }}>\omega_{\text {Defense Asexual; }}$ i.e., reduced rates of adaptive evolution) and a reduction in the magnitude of purifying selection

149 ( $\left.\omega_{\text {Non-defense Sex }}<\omega_{\text {Non-defense Asexual }}\right)$ that might facilitate the accumulation of deleterious mutations

150 as found by Hollister et al. (2015). 
154 annotations (GO) from Arabidopsis thaliana, we identified, filtered and aligned 721 defensive

155 and 1,710 non-defensive orthologous genes (table S1). We used Phylogenetic Analysis by

156 Maximum Likelihood (PAML) to analyze coding sequences to identify patterns of increased or

157 decreased molecular evolution across these 2,431 Oenothera genes. Specifically, we

158 compared changes in the strength and direction of selection between sexual versus

159 functionally asexual PTH lineages and between defense versus non-defensive genes to

160 investigate the influence of reproduction on the evolution of plant defense.

161

162

163

164

165

166 
167

168

169

170

171

172

173

174

175

176

177

178

179

180

181

182

183

184

185

186

187

190

188 Results

189 What is the distribution of positive and purifying selection strength across the

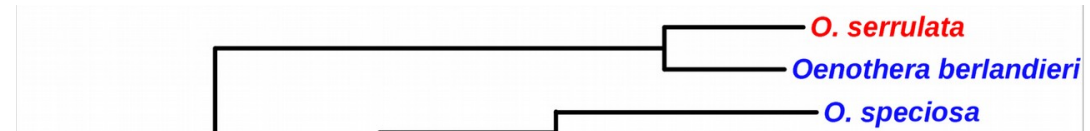

O. rosea

- O. suffulta

- O. filiformis

O. gaura

O. jamesii

Lo. elata hirsutissima

-O. elata elata

- O. wolfii

O. elata hookeri

O. longissima

- O. villosa villosa

O. villosa strigosa

-O. glazioviana

0 . stucchii

O. grandiflora

O. biennis

O. nutans

O. oakesiana

O. argillicola

- o. parviflora

一o. longituba

- O. nana

Lo. villaricae

- 0 . affinis

O. picensis

O. clelandii

O. rhombipetala

- O. laciniata

0. grandis

FIG. 2. Phylogenetic tree of the 32 Oenothera taxa included in the analyses. This tree is based

on the maximum likelihood phylogenetic tree generated by Hollister et al. (2015) using

RaXML (Stamatakis 2006) and 1.9Mb of concatenated sequences from 939 orthologous loci.

The node labels (1-7) indicate monophyletic clades; blue and red tips denote sexual and functionally asexual (PTH) Oenothera species, respectively.

\section{transcriptome of Oenothera?}


191 We inferred selection independently for each of the 2,431 orthologs (721 defense genes and

192 1,710 non-defensive genes) aligned across 32 taxa (16 sexual and 16 PTH) using PAML

193 (table S1). On average, proteins experienced purifying selection (the mean ratio of

194 nonsynonymous to synonymous substitution rates was $\omega_{\text {mean }}=0.216<1, \mathrm{n}=1969$ ), with the

195 signature of selection across codons ranging from intense purifying $\left(\omega_{0}=0.0001\right)$ to strong

196 positive $\left(\omega_{2}=8.493\right)$ selection (fig. $\left.3 A\right)$. In $56 \%$ of genes (709 out of 1260$)$, we detected

197 variation (i.e., heterogeneity) in selection among amino acid sites (table 1, test 1; fig. 3B, C,

198 D), indicating that some sites were subject to more selective constraint than others. We also

199 found that 57 out of 1919 genes (3\%) showed evidence of positive selection after accounting

200 for false-discovery rates (table 1, test 2).

201

202

203

204

205

206

207

208 
A)

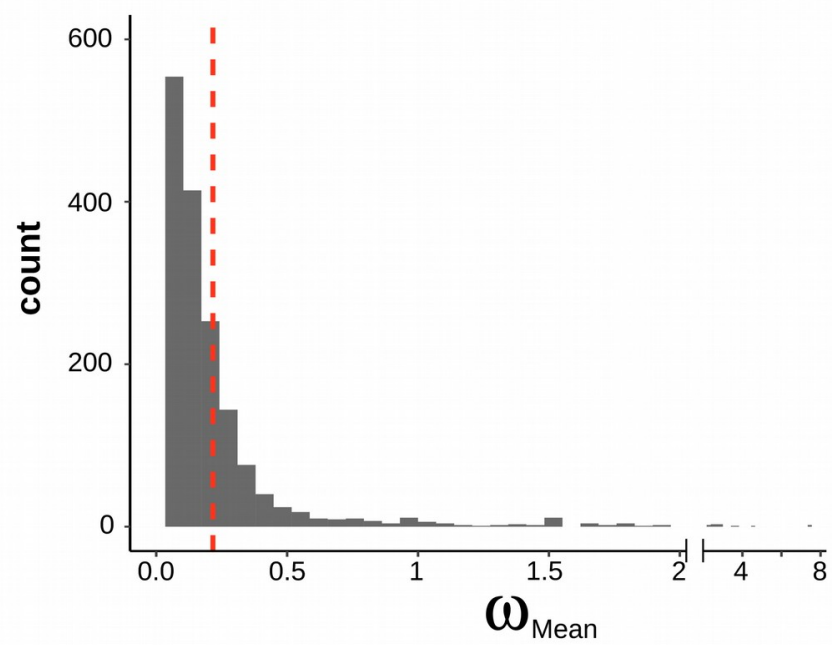

C)

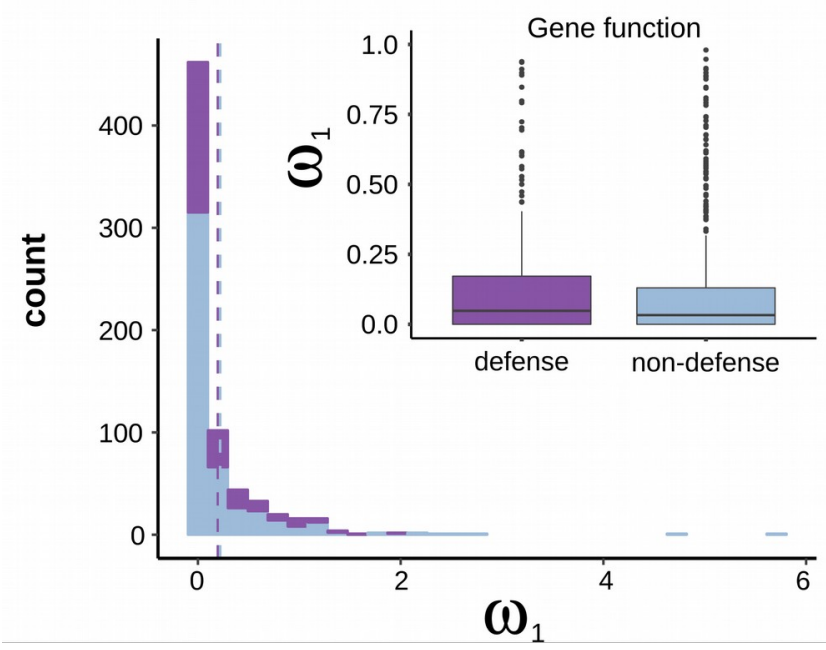

B)

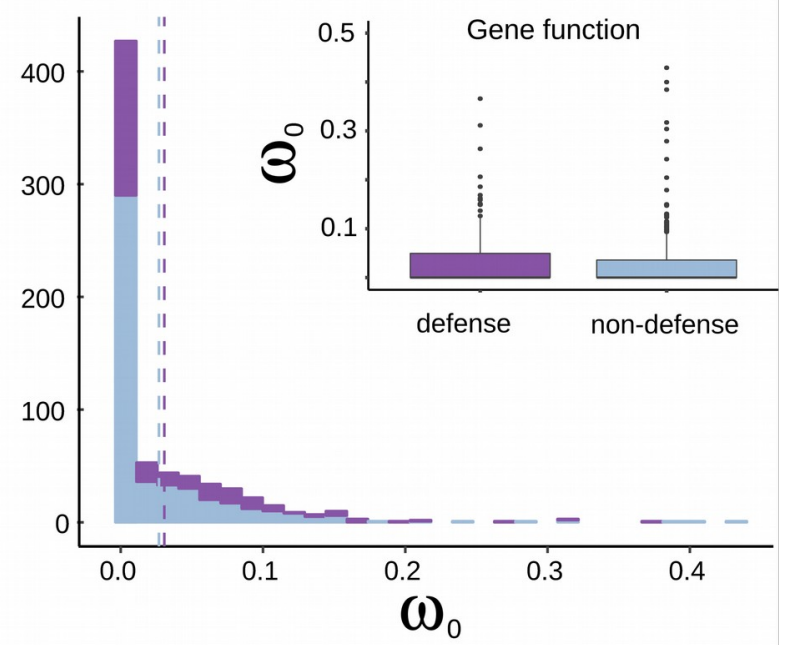

D)

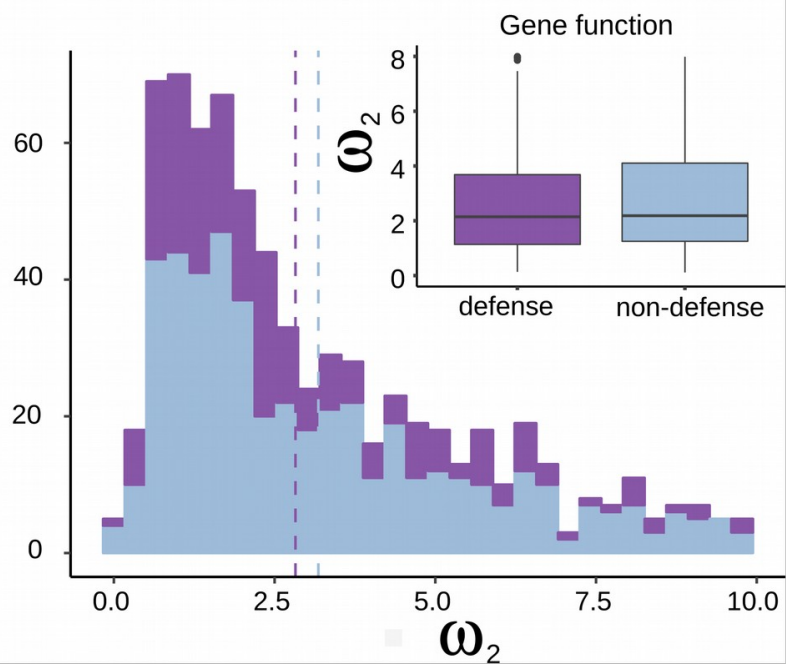

FIG. 3. A) Distribution of signature of selection on proteins $(\omega=$ rates of non-synonymous mutations/rates of synonymous mutations) for each gene when averaging the site and branch (one-ratio model); the dashed line indicates the mean value $(n=1969)$. The distribution of the signature of selection for three site types (B, C and D), indicating heterogeneity of $\omega$ values. In B-D, distributions of $\omega$ for defense (dark color) and non-defense (light color) genes are

215 plotted separately. Vertical dashed lines represent the mean value. 
Table 1. Six hierarchical tests (likelihood-ratio test contrasting null and alternative models from CODEML in PAML) were used to detect signatures of selection on amino sites, sex/PTH branches, and branch-site levels of variation. Each of these tests were performed on each of the 2,431 orthologs (721 defense orthologs, 1710 non-defensive orthologs). For each test (null vs alternative model) values of $\omega>10$ were removed, producing variation in the number of genes evaluated. For each test, the rejection and acceptance rate (per gene) of the null hypothesis (first and second number within parenthesis, respectively) as well as the \% rejection rate of the null hypothesis (bold) are reported. Acceptance and rejection rates are also separated by

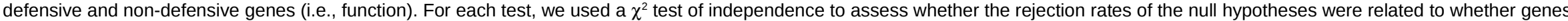
had a defensive function or not. We also present an explicit biological interpretation for each test between defensive and non-defensive functions. Rates of rejected null hypothesis are estimated from $P$-values after a Benjamini-Hochberg's false discovery rate correction.

\begin{tabular}{|c|c|c|c|c|c|c|}
\hline \multirow[b]{3}{*}{ Test } & \multirow[b]{3}{*}{$\begin{array}{l}\text { Interpretation of rejecting the } \\
\text { null hypothesis. } \\
\text { (Overall test) }\end{array}$} & \multicolumn{3}{|c|}{$\begin{array}{l}\text { Percentage of rejected null hypothesis } \\
\text { (rate of accepted null hypothesis; rejected null hypothesis) }\end{array}$} & \multirow[b]{3}{*}{$\begin{array}{c}\text { Independence test } \\
\text { (defense vs. no defense) }\end{array}$} & \multirow[b]{3}{*}{ Interpretation of the independence test } \\
\hline & & \multirow[b]{2}{*}{$\begin{array}{c}\text { Overall } \\
\text { test }\end{array}$} & \multicolumn{2}{|c|}{ Function } & & \\
\hline & & & Defensive & No defensive & & \\
\hline $\begin{array}{l}\text { Test } 1 \\
\text { (M0 vs M3) }\end{array}$ & $\begin{array}{l}\text { Site model: } \\
\text { Rejecting the null hypothesis } \\
\text { indicates selective heterogeneity } \\
\text { among amino acid (a.a.) sites } \\
\text { (purifying, neutral, and positive } \\
\text { selection). }\end{array}$ & $\begin{array}{l}36.01 \% \\
(709 ; 1260) \\
\text { total: } 1969\end{array}$ & $\begin{array}{c}39.63 \% \\
(233 ; 354) \\
587\end{array}$ & $\begin{array}{c}34.44 \% \\
(476 ; 906) \\
1382\end{array}$ & $\chi_{1}^{2}=4.704 ; P=0.030$ & $\begin{array}{l}\text { The discovery rate of heterogeneity between } \\
\text { amino acid sites is higher than in non-defensive } \\
\text { genes. }\end{array}$ \\
\hline $\begin{array}{l}\text { Test } 2 \\
\text { (M1a vs M2a) }\end{array}$ & $\begin{array}{l}\text { Site model: } \\
\text { Indicates that the heterogeneity } \\
\text { among a.a. site includes positive } \\
\text { selection at some sites. }\end{array}$ & $\begin{array}{c}2.97 \% \\
(57 ; 1862) \\
1919\end{array}$ & $\begin{array}{c}3.19 \% \\
(18 ; 545) \\
563\end{array}$ & $\begin{array}{c}2.87 \% \\
(39 ; 1317) \\
1356\end{array}$ & $\chi_{1}^{2}=0.053 ; P=0.818$ & $\begin{array}{l}\text { The discovery rate of amino acid sites under } \\
\text { positive selection are similar between gene } \\
\text { functions. }\end{array}$ \\
\hline $\begin{array}{l}\text { Test } 3 \\
\text { (M0 vs H1) }\end{array}$ & $\begin{array}{l}\text { Branch model: } \\
\text { Indicates a mean difference on } \\
\text { the overall signature of selection } \\
\text { between sexual and PTH } \\
\text { lineages. }\end{array}$ & $\begin{array}{c}1.04 \% \\
(23 ; 2177) \\
2200\end{array}$ & $\begin{array}{c}0 \% \\
(0 ; 661) \\
661\end{array}$ & $\begin{array}{c}1.49 \% \\
(23 ; 1516) \\
1539\end{array}$ & $\chi^{2}{ }_{1}=8.590 ; P=0.003$ & $\begin{array}{l}\text { The discovery rate of mean differences in the } \\
\text { overall signature of selection between sexual and } \\
\text { PTH lineages is higher in non-defensive genes } \\
\text { than in defensive genes. }\end{array}$ \\
\hline $\begin{array}{l}\text { Test } 4 \text { (for foreground SEX) } \\
\text { (Model A null vs. Model A) } \\
\text { (null model fixes omega2 = 1) }\end{array}$ & $\begin{array}{l}\text { Branch } x \text { site model } \\
\text { Indicates that part of the } \\
\text { heterogeneity among a.a. sites on } \\
\text { sexual lineages are due to sites } \\
\text { under positive. }\end{array}$ & $\begin{array}{c}0.40 \% \\
(8 ; 1969) \\
1977\end{array}$ & $\begin{array}{c}0.34 \% \\
(2 ; 594) \\
596\end{array}$ & $\begin{array}{c}0.43 \% \\
(6 ; 1375) \\
1382\end{array}$ & $\chi_{1}^{2}=0 ; P=1$ & $\begin{array}{l}\text { The discovery rate of positive selection on amino } \\
\text { acid. from sexual lineages is independent of gene } \\
\text { function. }\end{array}$ \\
\hline $\begin{array}{l}\text { Test } 5 \text { (for foreground PTH) } \\
\text { (Model A null vs. Model A) } \\
\text { (null model fixes omega2 = 1) }\end{array}$ & $\begin{array}{l}\text { Branch } x \text { site model } \\
\text { Indicates that part of the } \\
\text { heterogeneity among a.a. } \\
\text { detected on PTH lineages are due } \\
\text { to sites under positive. }\end{array}$ & $\begin{array}{c}0.15 \% \\
(3 ; 1964) \\
1967\end{array}$ & $\begin{array}{c}0.52 \% \\
(3 ; 576) \\
579\end{array}$ & $\begin{array}{c}0 \% \\
(0 ; 1388) \\
1388\end{array}$ & $\begin{array}{l}\chi^{2}{ }_{1}=4.202 ; P=0.040 \\
\text { Fisher's exact test; } \\
P=0.02\end{array}$ & $\begin{array}{l}\text { The discovery rate of positive selection on amino } \\
\text { acid. from sexual lineages is independent of the } \\
\text { gene function. }\end{array}$ \\
\hline $\begin{array}{l}\text { Test } 6 \\
\text { (M2a_ref vs CmC) }\end{array}$ & $\begin{array}{l}\text { Clade model } \\
\text { Explicitly test for divergent } \\
\text { evolution of genes between SEX } \\
\text { and PTH lineages. }\end{array}$ & $\begin{array}{c}2.71 \% \\
(44 ; 1578) \\
1622\end{array}$ & $\begin{array}{c}1.87 \% \\
(9 ; 473) \\
482\end{array}$ & $\begin{array}{c}3.07 \% \\
(35 ; 1105) \\
1140\end{array}$ & $\chi^{2}{ }_{1}=1.429 ; P=0.232$ & $\begin{array}{l}\text { The discovery rate of genes under divergent } \\
\text { evolution in sexual and PTH lineages are } \\
\text { independent of the gene function. }\end{array}$ \\
\hline
\end{tabular}




\section{Are defense genes subject to weaker purifying selection and stronger positive}

\section{selection than non-defense genes?}

Overall, we found that the signature of positive selection was similar between defense than non-defense genes. Of the 57 genes that experienced positive selection in Oenothera (see details in table S2), the probability of detecting positive selection was not significantly different between defense and non-defense genes (table 1, test 2). When estimating the signature of positive selection on individual codons, we found the mean omega was $\omega_{2}=5.804$ (site model), and there was no overall difference in the magnitude of positively selected sites between defense and non-defense genes $\left(\omega_{2 \text { defense }}=5.970, n=18 ; \omega_{2 \text { non-defense }}=5.727, n=39\right.$; Mann-Whitney Test: $U=348, P=0.580$ ) (table 1, test 2). However, the proportion of amino acid sites from those genes in which positive selection was detected, was nearly $2 x$ higher in defense genes ( $p_{2}$ (proportion of sites under positive selection) defense $\left.=0.262 \pm 0.047\right)$ than in nondefense genes ( $\left.p_{2 \text { non-defense }}=0.134 \pm 0.032\right)$ (randomized one-way ANOVA based on 1000 iterations: $F_{\text {obs: } 1,55}=4.954, P=0.027$ ) (fig. S1).

\section{Do sexual or PTH Oenothera species exhibit altered positive or purifying selection on}

\section{defense and non-defense genes?}

The signature of positive selection differed between sexual and PTH lineages in 23 out of 2177 genes (1\%). These differences were unrelated to whether genes had a role in defense (table 1, test 3). On average, reproductive modesshared a similar strength of purifying selection $\left(\omega_{\mathrm{SEX}}=0.299, \omega_{\mathrm{PTH}}=0.280 ; U=1121200, P=0.856\right)$. Site heterogeneity due to positive selection was 2.7 times more common in sexual (8 out of 1977 genes; $0.4 \%$ ) than in functionally asexual PTH lineages (3 out of 1967 genes; 0.15\%) (table 1, test 4 and 5; respectively), but the difference that was not statistically significant (table 1: test 4 vs. test 5 ; 
$\left.251 \chi_{1}^{2}=0.1438, P=0.230\right)$. The probability of detecting positive selection on defense genes was

252 also similar between sexual and PTH species $\left(\right.$ SEX $_{\text {defense }}=0.34 \%$ of all defense genes were

253 under positive selection; $\mathrm{PTH}_{\text {defense }}=0.52 \%$ of all defense genes were under positive

254 selection, Fisher's exact test: $P=0.683$; see table 1 test 4 vs. test 5 , column for defense

255 genes). However, in non-defensive genes, positive selection was more common in sexual

256 species $\left(\mathrm{SEX} \mathrm{X}_{\text {non-defensive }}=0.43 \% ; \mathrm{PTH}_{\text {non-defense }}=0.0 \%\right.$, Fisher's exact test: $P=0.015$; see table

2571 test 4 vs. test 5, column for non-defensive genes). Moreover, the signature of positive

258 selection was 7.58\% stronger in sexual than in PTH lineages (sexual: $\omega_{2}=4.315, n=8 ; \mathrm{PTH}$ :

$\left.259 \omega_{2}=4.011, \mathrm{n}=3\right)$, but this difference was not significant $(U=12, P=1)$. We found no

260 correlation between the magnitude of positive selection detected in sexual versus $\mathrm{PTH}$

261 lineages for defense or non-defense genes (defense: $r_{\text {Spearman's correlation }}=-0.009, \mathrm{n}=613, P=$ 
A)

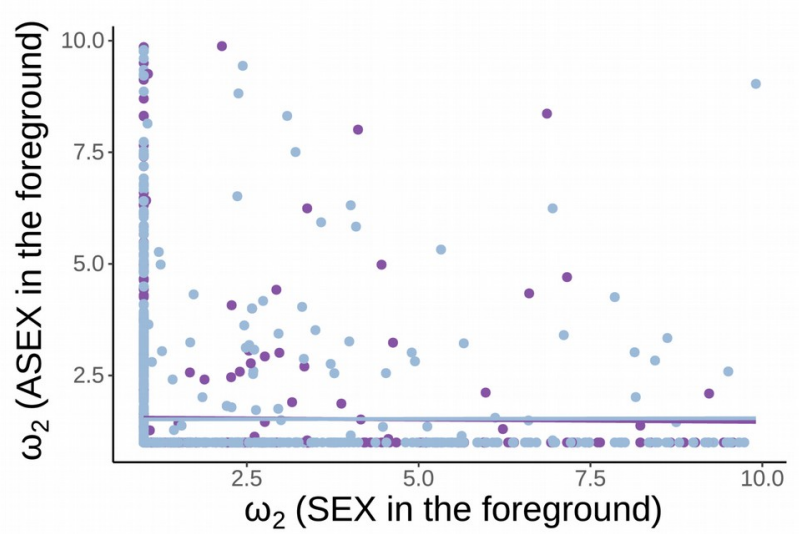

C)

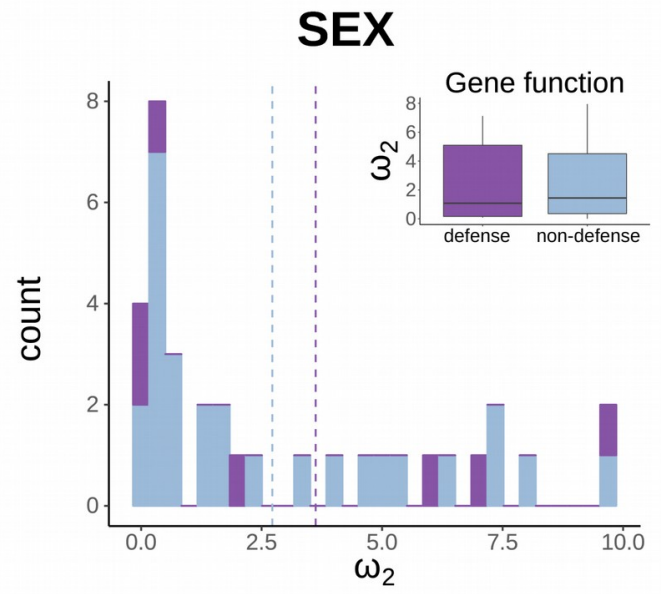

B)

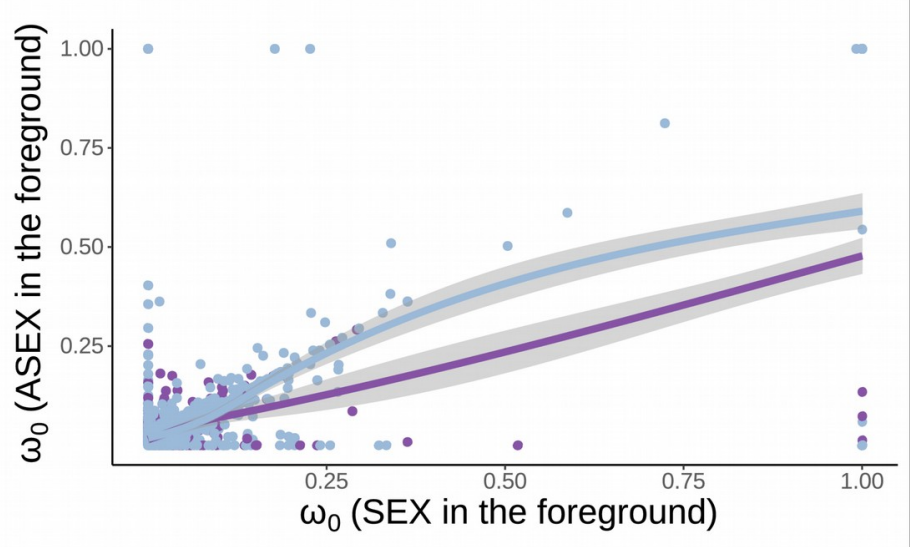

D)

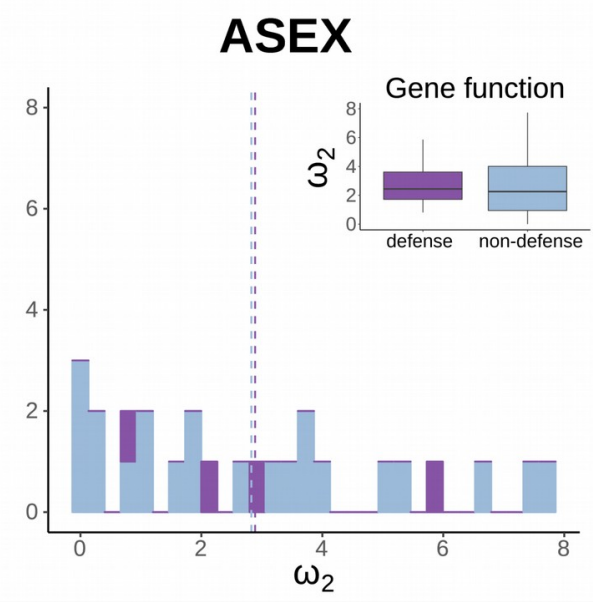

279 FIG. 4. A) Relationship between the signature of positive selection in sexual versus asexual

280 lineages and defensive (dark color) and non-defensive (light color) genes. B) Relationship

281 between the signature of purifying selection in sexual versus PTH lineages in defensive (dark

282 color) and non-defensive (light color) genes. Plots C and D show the distribution of the

283 magnitude of positive selection for sexual (C) and PTH (D) lineages by gene function. $\omega$

284 values were generated from an independent branch-site model performed for each gene.

285 Vertical dashed lines denote distribution means. 
(table 1, test 2), we obtained estimates of the strength of purifying selection. The overall

288

289

290

291

292

293 strength of purifying selection was $\omega_{0}=0.0671\left(n_{\text {overall }}=3944 ; n_{P T H}=1967, n_{\text {SEX }}=1977\right)$. The strength of purifying selection did not vary by sexual system (sexual: $\omega_{0}=0.0667, \mathrm{n}=1977$; PTH: $\left.\omega_{0}=0.0674, \mathrm{n}=1967 ; U=1972800, P=0.4082\right)$, or by gene function (defense: $\omega_{0}=$ $0.0671, \mathrm{n}=1175 ;$ non-defense: $\left.\omega_{0}=0.0670, \mathrm{n}=2769 ; U=1644900, P=0.564\right)$. There was a positive correlation in the strength of purifying selection acting on gen The strength and direction of selection on a given pres between sexual and PTH lineages (fig. 4B), and the strength of this relationship was higher for non-defensive genes than defense genes (Nondefense: $r_{\mathrm{s}}=0.640, \mathrm{n}=1271, P<0.0001$; Defense: $r_{\mathrm{S}}=0.544, \mathrm{n}=613, P<0.0001$; ScheirerRay-Hare (SRH) Test: genetic system $\times$ defensive function: $\left.\chi^{2}{ }_{1}=4.436, P=0.035\right)$.

otein might differ between sexual and functionally asexual PTH species due to relaxed purifying selection, or changes in positive selection favoring divergent protein evolution (i.e. $\left.\omega_{\mathrm{PTH}} \neq \omega_{\mathrm{SEX}}\right)$. We detected divergent evolution in $2.8 \%$ of the genes examined (44 out of 1578). Divergent selection was $68.8 \%$ more common in non-defensive than in defense genes, but this difference was not statistically significant (table 1, test 6). The mean magnitude of selection on divergent genes was $\omega=1.96$, with selection being higher in sexual lineages $\left(\omega_{\mathrm{SEX}}=2.246, \mathrm{n}=44\right)$ than PTH lineages $\left(\omega_{\mathrm{PTH}}=1.675, \mathrm{n}=44\right)$. Despite these differences, there was no significant effect of sexual system, gene function (defense/no defense), or their interaction on the magnitude of $\omega$ (SRH Test: genetic system: $\chi^{2}{ }_{1}=1.471, P=0.225$; defensive function: $\chi^{2}{ }_{1}=0.147, P=0.701$; genetic system $\mathrm{x}$ defensive function: $\chi^{2}{ }_{1}=0.384, P$ $=0.535$ ) (fig. 4C, D, table 2). Surprisingly, divergent evolution caused by positive selection (i.e., when either $\omega_{\mathrm{PTH}}, \omega_{\mathrm{SEX}}$, or both are > 1), was more frequent in PTH (32 out of 1140; $2.8 \%)$ than in sexual lineages (0 out of 482$)\left(\chi^{2}=12.02 ; P=0.0005\right)$. 
311 Table 2. Overall magnitude of signature of selection (including purifying and positive selection) on genes under divergent evolution; the estimates are for the full $2 \times 2$ factorial design (sexual and PTH reproduction, defense and non-defensive function). We predicted that divergent evolution would be more common and stronger in defensive versus non-defensive genes. $\omega$ values were estimated from $\mathrm{CmC}$ model; the table includes those genes where divergent selection was detected (table 1, test 6). A Scheirer-Ray-Hare test did not detect differences between genetic system, gene function, or the interaction between genetic system x gene function (statistics reported in Results).

319

\begin{tabular}{|c|c|c|c|}
\hline & & \multicolumn{2}{|c|}{ Magnitude of signature of positive selection $\left(\omega_{2}\right)$} \\
\hline & & \multicolumn{2}{|c|}{ Genetic system } \\
\hline & & $\begin{array}{l}\text { Sexual reproduction } \\
(\text { Sex })\end{array}$ & $\begin{array}{c}\text { Asexual reproduction } \\
\text { (PTH) }\end{array}$ \\
\hline \multirow{2}{*}{$\begin{array}{c}\text { Gene } \\
\text { function }\end{array}$} & Defense & $\begin{array}{c}2.81 \pm 1.26 \\
(n=9)\end{array}$ & $\begin{array}{c}1.28 \pm 0.67 \\
(n=9)\end{array}$ \\
\hline & Non-defensive & $\begin{array}{c}2.09 \pm 0.45 \\
(n=35)\end{array}$ & $\begin{array}{c}1.77 \pm 0.39 \\
(n=35)\end{array}$ \\
\hline
\end{tabular}

\section{Defense genes under positive and divergent evolution}

The identities of defense and non-defensive genes subject to positive selection (based on tests 4 and 5, table 1) and divergent evolution (based on test 6 from table 1) are shown in table S2. Our GO enrichment analysis focused on defense genes subject to positive selection, which detected three enriched functional terms: cell division, cell cycle and defense responses to virus (see statistics on table S3 and graphical representation of enrichment analysis and GO structure of the first five enriched nodeson fig. S2 and S3, respectively). Moreover, defense genes with evidence of divergent evolution (from test 6), were enriched for functions including: defense response, stress activated protein kinase signaling cascade, and 
regulation of mitotic cell cycle (see statistics on table S4 and extra information on fig. S4 and S5).

We found that defense genes subject to positive selection and divergent evolution were associated with constitutive and induced defenses and various functions within the immune plant system that mediate detection, signalling and response to pathogens. For instance, levels of constitutive defense are affected by the genes Nup96, AGO4, and ARL8C/ARL8A, all of which were under positive selection (table S2 and S5). In addition, induced defenses are affected by genes we found to be subject to positive selection such as BGLU23, MED25, EDR1, and PSL4. Table S5 summarizes the identity, signature of selection, and the function of those defense genes under positive selection and divergent evolution (described in table S3 and S4, respectively). The general trend was for positive selection in genes that mediate the immune response (table S5).

\section{Discussion}

Theory predicts that antagonistic coevolution between hosts and parasites will cause host's defense genes to evolve more rapidly than non-defensive genes, and this effect will be most prevalent in sexual compared to asexual hosts (Levin 1975; Otto and Nuismer 2004; Lively 2010; Johnson et al. 2015). Although several studies have shown that a reduction in recombination and segregation results in an accumulation of deleterious mutations (Gray and Goddard 2012; Henry et al. 2012; Hollister et al. 2015; Hussin et al. 2015; Lovell et al. 2017), we are unaware of any genome-wide tests of whether adaptive molecular evolution varies at a macroevolutionary scale between sexual and asexual taxa (but see Roth and Liberles 2006). In an examination of protein evolution in 2,431 genes (721 defensive and 1,710 nondefensive genes), sampled from 32 taxa (16 sexual and 16 functionally asexual PTH species 
and subspecies) of Oenothera, we detected heterogeneity in the rate of protein evolution in over half of the genes (709 genes out of 1260; see test 1 table 1 ) and positive selection in $3 \%$ of the genes (57 genes out of 1862; see test 2 in table 1 ). Although the proportion of sites per gene under positive selection was more frequent in defense genes, the signatures of selection were surprisingly similar between defensive and non-defensive genes in sexual and PTH lineages of Oenothera that emerged $\sim 5 \mathrm{~K}$ to $500 \mathrm{~K}$ years ago (Hollister et al. 2015).

These results suggest that transitions to the functionally asexual PTH genetic system have not strongly influenced signatures of positive selection in Oenothera. Such similarities might be due to a combination of a short period of time for contrasting adaptive evolution to leave a clear signature, strong demographic stochasticity inherent to Oenothera, and the conservative nature of our tests of protein evolution both. Below we discuss the implications of our results in the context of the molecular evolution of plant defenses and the evolutionary consequences of losing sexual reproduction for adaptive molecular evolution.

\section{Molecular evolution of plant defense}

We investigated the prediction that defense genes experience stronger positive selection than non-defense genes at a macroevolutionary scale. This prediction was based on the knowledge that plants and their parasites undergo reciprocal natural selection (Ehrlich and Raven 1964; Janzen 1980; Thompson 1998), which can result in coevolution. This coevolution alters selective pressure on defense genes through time and space (Gomulkiewicz et al. 2000; Nuismer et al. 1999; Thompson 2005). By contrast, many nondefense genes have core metabolic and developmental functions and thus their evolution is generally expected to be more constrained resulting in purifying selection. In addition to stronger and more frequent positive selection, we also expected weaker purifying selection on defense genes than on non-defense genes. Although the signature of purifying and positive 
selection was similar between defense and non-defensive genes, the proportion of of positively selected sites per gene was higher in defense than non-defense genes. Thus, if there are differences in positive selection between defense and non-defense genes, they are small and difficult to detect in Oenothera.

An increasing number of studies have reported positive selection on defense genes.

These studies have mainly focused on genes associated with the pathogen parasite detection (R-genes) and defensive response (pathogenesis response proteins; PR) of the plant immune system. There is much less information on how selection acts on signaling and metabolic pathways (Tiffin and Moeller 2006) that can be involved in the immune response, such as in the WKYR family of genes (but see Wang et al. 2011). The region involved in pathogen identification (LRR domain of R-genes), is among the best studied cases of molecular evolution in response to selection (Meyers et al. 1998; Bergelson et al. 2001a; MondragónPalomino et al. 2002; Mauricio et al. 2003). This domain is highly variable wtihin species and shows a signature of molecular evolution consistent with balancing selection, suggesting that parasites drive frequency-dependent selection on R-gene evolution (Stahl et al. 1999; Tian et al. 2002; Caicedo and Schaal 2004; Rose et al. 2004; Bakker 2006; Karasov et al. 2014). Positive selection has also been detected in pathogenesis response proteins (PR), such as class I chitinase in Arabis and Oenothera (Bishop et al. 2000; Hersch-Green et al. 2012), threonine deaminase duplications involved in defense (e.g., TD2, Rausher and Huang 2015), and genes involved in terpenoid biosynthesis (Ramsay et al. 2009; Scherer et al. 2005).

Together these studies indicate that at least some defense genes do show clear signatures of adaptive molecular evolution.

The studies reviewed above suggest several factors may be important in determining whether or not defense genes are likely to experience positive selection. For example, gene duplications can relax selective constraints and enable sequence diversification on genes 
403

404

405

406

407

408

409

410

411

412

involved in secondary metabolism (Rausher and Huang 2015; Talyzina and Ingvarsson 2006; des Marais and Rausher 2008). The position of genes within metabolic pathways, such as whether they are upstream/downstream, or at critical junctures in controlling flux, can also have large effects on evolutionary constraints (Rausher et al 1999; Flowers et al. 2007; Ramsay et al. 2009; Eanes 2011), and the likelihood of exhibiting positive selection (Flowers et al 2007; Wright and Rausher 2010). Similarly, many adaptive changes are expected to affect gene regulation and expression rather than altering the structure of metabolic proteins (Shapiro et al. 2004; Hoekstra and Coyne 2007; Wray 2007; Carrol 2008). Finally, life-history variation among hosts can also affect patterns of positive selection and divergence of $\mathrm{R}$ genes between lineages (Chen et al. 2010). Despite the mounting evidence, little is known about the overall contrasting signature of selection between defensive and non-defensive genes (but see Roth and Liberles 2006). Particularly, none of these works have focused explicitly on whether the molecular evolution of plant defenses is affected by the loss of sex. In this context, and from a macro-evolutionary perspective, the Oenothera system may yield valuable insights.

Why did we not see clearer differences in the signatures of selection on defense and non-defense genes given previous reports of positive selection on defense genes? One obvious explanation is that many defense genes are likely to be under strong evolutionary constraints. These constraints can arise when defense proteins act as core enzymes in metabolic pathways, conferring pleiotropic effects on defensive and non-defensive plant functions. For example, chalcone synthase is an upstream gene in the flavonoid pathway, and in addition to the production of defensive metabolites, this pathway produces numerous secondary metabolites involved in pigmentation and mitigation of abiotic stresses (Rausher 2008). Thus, it may be downstream genes with few pleiotropic effects, or recently duplicated genes with relaxed selective constraints, that are more likely to experience positive selection. 
Alternatively, only a small fraction of the defensive system maybe involved in co-evolution, and these genes may be biased to having a regulatory function on defensive response. Another possible explanation for the lack of a clear difference in protein evolution between defense and non-defense genes is that Red Queen coevolutionary dynamics are the dominant mode of coevolution between plants and their parasites, as opposed to escalating arms-race coevolution (Stahl et al. 1999; De Meaux and Mitchell-Olds 2003). Under the Red Queen model, negative frequency-dependent selection maintains polymorphisms at defensive loci, which would prevent the fixation of new alleles and thus the detection of positive selection (Bakker 2006; Karasov et al. 2014; Sicard et al. 2015). By contrast, the arms-race model is expected to favor the fixation of new alleles that increase resistance against an increased virulence in the pathogen (Bergelson et al. 2001a, b). These two possibilities are best distinguished through a comparative population genetics approach, in which patterns of within-species molecular genetic variation are examined alongside sequence from recently diverged species or populations (e.g., McDonald and Kreitman 1991; Fumagalli et al. 2015; Lamichanney et al. 2015). A third and related possibility is that defensive genes do in fact evolve rapidly, so much so that they frequently have no detectable homologue with $A$. thaliana (Schmid and Tautz 1997), and identification of orthologs within Oenothera maybe difficult to detect and align. In such cases, defense genes would have been filtered out when we identified orthologs. Indeed, our approach of identifying defense genes based on annotated functions on $A$. thaliana will be inherently conservative. It is likely that a combination of these explanations account for the similar signatures of positive and purifying selection on defense and non-defense genes in Oenothera. 
452

453

454

455

456

457

458

459

460

461

462

463

464

465

466

467

468

469

470

471

472

473

474

475

476

The main goal of our research was to determine whether the strength and direction of selection on defense and non-defense genes is affected by a loss of sexual reproduction.

Based on theory and empirical studies, we predicted more efficient selection in sexual than functionally asexual PTH Oenothera species (Levin 1975; Otto and Nuismer 2004; Lively 2010; Hersch-Green et al. 2012; Hollister et al. 2015; Neiman et al. 2017). Specifically, we expected to observe stronger and more frequent positive selection on defense genes and stronger purifying selection on non-defense genes in sexual lineages than in PTH lineages (fig. 1). Despite detecting some cases in which defensive and non-defensive proteins were evolving in contrasting ways between genetic systems (see discussion below), on average we found a similar frequency and magnitude of positive selection on defense and non-defense genes in both sexual and PTH lineages.

Although theory and a growing body of research support a general trend for a reduced efficacy of natural selection with lower effective rates of recombination (see table 1 in Hartfield 2015; Gos et al. 2012; McDonald et al. 2016) and segregation (Agrawal 2009), there are notable exceptions. For instance, in a comparison of a selfing plant species (Capsella rubella) with low effective rates of recombination, to its outcrossing sister taxon (C. grandiflora) with higher effective rates of recombination, Gos et al. (2012) detected no difference in balancing selection on R-genes. This lack of a difference was in part attributed to the maintenance of an ancestral polymorphism within C. rubella. In other studies, in which no contrast between defense and non-defensive function was evaluated, similar substitutions rates (i.e., $\omega$ ) were found when comparing genes from outcrossing and selfing species, for instance in selffertilizing A. thaliana versus self-incompatible species A. lyrata (Wright et al. 2002; but see Payne and Alvarez-Ponce 2018) or selfing versus outcrossing Caenorhabditis species (Cutter et al. 2008) (also see Haudry et al. 2008). Likewise, when comparing substitution rates between contrasting genetic systems, two genome-wide studies did not find contrasting 
fixation rates either between sexual and asexual genotypes of Daphnia pulex (Tucker et al. 2013), or between sexual and asexual aphid species (Ollivier et al. 2012). Below, we discuss some possible explanations to why we might have found similar signature of selection between sexual and asexual species (also see Hartfield 2015).

The young age of many asexual lineages is one possible explanation for finding similar patterns of adaptive evolution between sexual and asexual lineages (Wright et al. 2002;

Cutter et al. 2008; Tucker et al. 2013). When lineages are young there may be insufficient time to generate contrasting patterns of molecular evolution between lineages with different reproductive systems. In Oenothera, functionally asexual PTH lineages emerged $\sim 5 \mathrm{~K}$ to $500 \mathrm{~K}$ years ago (Hollister et al. 2015). This may have been too short a period of time for adaptive evolution to result in different signatures of positive selection on many genes between sexual and functionally asexual species. Nevertheless, we did detect divergent selection between sexual and PTH lineages on a small number of specific genes (see discussion below for examples). Similarly, Hersch-Green et al. (2012) detected a single defensive protein that exhibited positive selection in sexual but not asexual Oenothera lineages, and previous work found divergent patterns in the expression of defenses and susceptibility to herbivory between sexual andasexual species (Johnson et al. 2009; Johnson et al. 2014). Thus, the short period of divergence between sexual and asexual species may only be a partial and non-universal explanation for similar signatures of positive selection between sexual and PTH Oenothera. Reduced recombination and high demographic stochasticity in sexual species may also explain a lack of difference in positive selection between sexual and PTH Oenothera. Sexual Oenothera experience dramatically reduced recombination rates, even when segregation of alleles matches expectations from typical sexual reproduction (Rauwolf et al 2011). Likewise, both sexual and asexual Oenothera species exhibit similar growth and lifehistory strategies, including most species occurring in small patchy populations that are rarely 
at equilibrium, with many species exhibiting low effective population sizes (Hollister et al.

2015). These observations of suppressed recombination rates and high demographic

stochasticity in sexual as well as asexual species may reduce the efficiency of selection on adaptive alleles in both sexual and PTH taxa.

Despite these caveats, previous work in this system suggests that enough time has

passed to detect contrasting patterns of accumulation of deleterious mutations and

heterozygosity, at least when the entire transcriptome is compared between closely related sexual and PTH lineages (Hollister et al. 2015). In contrast to the results of Hollister et al. (2015), we did not find clear differences in purifying selection, likely because of the smaller number of proteins examined, and a reduction on the statistical power due to including in our final analyses only genes under positive selection detected by PAML-based likelihood-ratiotests models, such as branch-site and clade models, instead of using PAML free models as was done by Hollister et al. (2015). Thus, while adaptive evolution may not on average differ between sexual and functionally asexual Oenothera, with large transcriptome-wide samples, there is evidence for differences in selective constraint acting between sexual and PTH lineages.

\section{Defense genes under positive selection}

The defense genes that were identified to be subject to positive selection or divergent evolution were associated with constitutive and induced defenses mediating the production of secondary metabolites and defense-related hormones such as salicylates (SAs) and jasmonates (JAs) (see table S2 and table S5). For instance, we found divergent evolution of the gene Nup96 between sexual and PTH lineages $\left(\omega_{\mathrm{SEX}}=1.892, \omega_{\mathrm{PTH}}=0.0\right.$; table S5). Suppression of this gene reduces constitutive and basal (i.e., innate immunity also called non-host resistance) defense because it encodes a nucleoporin protein involved in nuclear mRNA exporta- 
tion that mediates the expression of pathogenesis-related (PR) R-genes such as snc1 and $R P P 4, R P M 1, R P S 4$, which are involved in the susceptibility of plants to bacteria and fungi (Zhang 2005). In concert with Nup85, Nup133 and Seh1, Nup96 is also implicated in plant responses to symbiotic microbes (Wiermer et al. 2012). Another gene affecting the basal layer of defense evolving divergently between sexual and PTH species $\left(\omega_{\mathrm{PTH}}=2.865, \omega_{\mathrm{SEX}}=0.123\right.$; table S5) is argonaute 4 (AGO4). AGO4 binds small RNAs and mediates target RNA regulation to induce DNA methylation (RNA-directed DNA methylation; RdDM) and histone modifications that modulate the host immune system (Agorio and Vera 2007; Weiberg et al. 2014). Genes involved in induced responses were also detected under positive selection. For example, the gene MED25, which mediates the expression of jasmonate-dependent defenses and resistance against necrotrophic fungal pathogens (Kidd et al. 2009), was detected under positive selection exclusively in PTH species (OG0002218; $\left.\omega_{2}=2.726\right)$. Similarly, the gene $B G L U 23$, which is a PYK10-type $\beta$-glucosidase associated with the methyl jasmonate-induced endoplasmic reticulum bodies in roots (Sherameti et al. 2008; Ahn et al. 2010) also showed evidence of positive selection ( $\omega_{2}=8.308$; orthogroup: OG0001781; table S5). In general, these examples and the others shown in table S5, illustrate that beside R-genes there are multiple regulatory genes (Hoekstra and Coyne 2007; Wray 2007; Carrol 2008) involved in the immune response which are a target of selection and potentially evolving under a coevolutionary dynamic with parasites (e.g., argonaute genes and Nup96). Interestingly, the propensity for divergent selection to be more common in PTH lineages than sexual lineages is consistent with theoretical predictions that asexual reproduction can facilitate divergent evolution more than sexual reproduction under scenarios of disruptive selection (Dieckmann and Doebeli 1999).

\section{Conclusions}


552 Our results challenge existing theory relating to the evolution of plant defense and the

553 evolution of sex. Traditionally, most analyses on the evolution of defense have focused on the

554 molecular evolution of individual defense genes or gene families. We are unaware of any

555 study that has contrasted molecular evolution of defense and non-defense genes genome-

556 wide at a macroevolutionary scale. Hence, the view that defense genes are subject to rapid

557 evolution within the genome, and disproportionately involved in such processes as speciation

558 (Bomblies et al. 2007), may be biased towards genes already known to be subject to rapid

559

560

561

562

563

564

565

566

567

568

569

570

571

572 evolutionary dynamics caused by negative frequency-dependent selection (e.g., Tian et al.

2002 PNAS). Here, we used a genome-wide analysis to gain a general understanding of the evolution of defensive genes in the genus Oenothera, and to test the expected benefit of sex for adaptive evolution. Our results challenge the view about the benefits of sexual reproduction for the coevolutionary process as it relates to the molecular evolution of defense genes. Specifically, our results do not support the predicted benefit of sexual reproduction on adaptive protein evolution of defense genes, either by increasing the adaptive rates of evolution or the efficiency of purifying selection. Moreover, the fact that defense and nondefensive genes showed a similar signature of selection on average, suggests that the coevolutionary process is insufficient to generate a consistent difference between defense and non-defense genes. Together, these two results call into question the prediction that the loss of sex consistently affect adaptive evolution due to plant-parasite interactions at a genome-wide scale. However, our results also suggest that a small number of specific genes related to plant immune function may be affected by a loss of sex. 


\section{Materials and Methods}

574

575

576

\section{Study System}

The monophyletic genus Oenothera includes 145 species (Wagner et al. 2007), of which 85\% exhibit sexual reproduction (Johnson et al 2009) characterized by bivalent pairing of 7 chromosome pairs $(2 x=14)$, free segregation of homologous chromosomes, and self or cross-fertilization (Cleland 1972). The remaining species exhibit a functionally asexual genetic system called permanent translocation heterozygosity (PTH). This genetic system occurs following reciprocal translocations of chromosome end-segments that alter chromosomal homology. This causes a large meiotic ring involving all 14 chromosomes of the two haploid sets ( $\alpha$ and $\beta$ ) (Cleland 1972; Rauwolf et al. 2008; Golczyk et al. 2014). The ring suppresses free segregation of the chromosomes between the haploid sets and establishes regularly segregation of them as a whole in two superlinkage groups. Moreover, suppression of homologous recombination avoids genetic reshuffling between the two haploid sets. Hence, the individual haploids sets $\alpha$ and $\beta$ are inherited as a unit without intermixing. Sex-linked inheritance and balanced lethal mortality of gametes effecitvely eliminates homozygous zygotes ( $\alpha \cdot \alpha$ or $\beta \cdot \beta)$ (Cleland 1972; Rauwolf et al. 2008). Finally, self-fertilization is nearly $100 \%$ because pollen dehisces onto receptive stigmas before flowers open. This results in permanently fixed heterozygosity of haploid genomes $(\alpha \cdot \beta)$, which is identical to the parental plant. Likewise, all seeds derived from selfing in a PTH individual are clones of one another and their parent plant (Cleland 1972; Rauwolf et al. 2008; Golczyk et al. 2014). PTH has evolved independently over 20 times, making it a naturally replicated experiment to understand how impaired sexual reproduction affects evolution (Johnson et al. 2009, Ranganath 2008). 


\section{Experimental design, sample preparation and genomic data}

The current study builds on our previous work examining the evolutionary genomic consequences of the functionally asexual PTH genetic system in Oenothera (Hollister et al. 2015; table $S 6$ maps basic information between both studies). Using a RNA-Seq transcriptome dataset generated by the 1KP project (Johnson et al. 2012; Matasci et al. 2014) and additional RNA-seq data, Hollister et al. (2015) focused on how evolutionary transitions between sexual and PTH reproduction affect protein evolution in each of seven clades of Oenothera. For each gene and clade, they estimated average dN/dS ratios using free-ratio models in PAML and found that on average PTH lineages experienced relaxed purifying selection (i.e., $d N / d S_{\text {sexual }}<d N / d S_{\text {PTH }}<1$ ). Here we build on our earlier work by specifically testing how a loss of sex affects the signature of positive and purifying selection on proteins, including how gene function, specifically defense vs non-defense genes, affect protein evolution. We provide a brief description of our methods here and refer readers to our previous work for detailed methods related to sample collection, preparation and sequencing (Johnson et al. 2012; Hollister et al. 2015).

Oenothera species were sampled to maximize phylogenetic diversity and the number of independent evolutionary transitions between sexual and PTH reproduction (fig. 2). We grew 62 individual plants from 32 species and subspecies (see table S6) from seed in controlled conditions, which included a minimum of ten independent transitions between sexual and PTH reproduction across the phylogeny. The fourth true leaf was collected from each plant at the same developmental stage. These leaves were flash-frozen and stored at $-80^{\circ} \mathrm{C}$ until extraction of total RNA. RNA extraction was performed using a hybrid CTAB/acid phenol/silica membrane method described in Johnson et al. (2012). The transcriptome library was prepared by BGI-Shenzhen (Shenzhen, China) and the North Carolina State University's 
622

623

624

625

626

627

628

629

630

631

632

633

634

635

636

637

638

639

640

641

642

643

644

645

646

Velvet Oases, run under default parameters (Schulz et al. 2012), as described by Hollister et al. (2015). We sequenced on average 2.5 billion nucleotides and assembled $\sim 22,100$ unique transcripts $>300$ nucleotides in length per sample.

\section{Genomic analysis}

We used TAIR GO annotations (ATH GO GOSLIM file; March 2016) to identify defense and non-defense protein sequences. Assembled Oenothera transcripts were compared to the $A$. thaliana genome using BLAST and sorted into defense vs. non-defense protein libraries based on an e-value $\leq 10^{-10}$ filter cut-off. We retained all defense genes identified ( $n=1,232$; see table S1) and randomly selected 2,000 annotated proteins to generate the non-defensive library. These two libraries were then subject to tBLASTp searches against each of the 62 (plus 1 extra individual) assembled transcriptomes, where nine of 32 taxa had multiple individuals sequenced per species. This within species genetic variation was controlled by removing redundant loci using an all-against-all BLASTn approach where only one sequence was retained if multiple loci had $>99 \%$ similarity with others. The removal of polymorphic and heterozygous sites ensured valid interpretations of $\mathrm{dN} / \mathrm{dS}$ ratios because estimates of selection by PAML are based on rates of fixed differences between species (Kryazhimskiy and Plotkin 2008).

We identified orthologs through several bioinformatic filtering steps. A custom Python script was used to identify the longest open reading frame (ORF) for each locus. ORFs were then translated into amino acid sequence and OrthoFinder (version 0.4.0; Emms and Kelly 2015) was used to create two new defense and non-defense ORF libraries comprised of unique orthogroups; each unique orthogroup contained orthologs and paralogs. In total, we identified 5,649 defensive and 13,457 non-defensive orthogroups. Paralogs were identified if more than one locus from the same species was included in the orthogroup, indicating a gene 
647

648

649

650

651

652

653

654

655

656

657

658

659

660

661

662

663

664

665

666

667

668

669

670

duplication; in such cases, all loci from the same species included within an orthogroup were removed. Such orthogroups were built by the OrthoFinder's algorithm that used a gene length and phylogenetic distance normalization of the all-against-all BLAST bit scores. The final number of orthogroups was reduced by further filtering (see below) so that each species had a maximum of one amino acid sequence per orthogroup (defense $=721$; Non-defense: 1,710 ; see table S1). Following the removal of paralogs, we converted the orthogroup sequences back into nucleotide sequences and compiled all orthologous nucleotide sequences into one FASTA file per locus (hereafter referred to as orthologs). Species' nucleotide sequences for each ortholog were then aligned using a translator alignment based on MUSCLE version 3.8.31 (Edgar 2004) implemented as part of a custom Python script. This ensured that the mutlisequence alignments (MSA) based on nucleotide sequences followed a codon structure (e.g., in-frame and gap distribution) for subsequent PAML analysis.

We manually curated and filtered the MSA of each ortholog before running PAML

(Anisimova et al. 2001; Yang and Dos Reis 2011). We excluded orthologs with $<150$

nucelotides (50 a.a.) and > 50\% gap sequence in the MSA using PAML's option "cleandata $=1 "$. To maintain sufficient statistical power, we retained MSAs that contained a minimum of 3 sexual and 3 PTH species as per the recommendations of PAML FAQ (goo.gl/58VU9C). A final visual examination and hand curation of the MSA was performed on every orthogroup previously filtered to ensure accurate alignments.

\section{Phylogenetic Analyses by Maximum Likelihood (PAML)}

Protein evolution at the codon level was assessed on each ortholog using maximumlikelihood implemented in PAML (Yang 2007). This analysis compared the ratio of nonsynonymous to synonymous substitution rates $(\omega=d N / d S)$ among lineages and codon 
671

672

673

674

675

676

677

678

679

680

681

682

683

684

685

686

687

688

689

690

691

692

693

694

sites to estimate the signature of selection. Equal non-synonymous and synonymous

substitution rates $(\omega=1)$ are considered consistent with neutral evolution (Li et al. 1985).

Higher nonsynonymous than synonymous substitutions are expected under positive selection

$(\omega>1)$, and lower nonsynonymous than synonymous substitution rates are expected to occur with purifying selection $(\omega<1)$ (Li et al. 1985; Nei and Gojobori 1986; Yang and Bielawski 2000).

The maximum likelihood phylogenetic tree reported by Hollister et al. (2015) was used to create specific phylogenetic trees for each set of orthologs. The original tree was estimated by Hollister et al. (2015) using RaXML version 7.0.4 (Stamatakis 2006), and it includes the 62 Oenothera experimental individuals, and it was based on $1.9 \mathrm{Mb}$ of concatenated sequences from 939 orthologous loci. The tips containing multiple individuals per species were collapsed to obtain a tree with one species per tip. Each phylogenetic tree was unrooted and pruned to match the species included in each MSA file.

Using CODEML in PAML, we used "site models", "branch models", "branch-site models", and "clade models" to answer our research questions about the signature of selection on defensive and non-defensive genes in sexual and PTH Oenothera. For each defense and non-defensive gene, a set of different models were performed to test our questions. Site models were used to test for variation in $\omega$ among amino acid sites (M0 vs. M3; table 1, test 1), and explicitly to test for the presence of a positively selected class of sites (M1a vs. M2a; table 1, test 2) (Nielsen and Yang 1998; Yang et al. 2000), which allowed us to answer question 1. A branch model was used to evaluate if overall $\omega$ values varied between sexual and PTH lineages (MO vs H1; table 1, test 3) (Yang 1998). For each defense and nondefensive gene, branch-site models were used to detect if positive selection at individual amino acid sites varied between sexual or PTH-lineages. Differences between the null (Model 
695

696

697

698

699

700

701

702

703

A null) and the alternative model (Model A) in branch-site models indicate that the presence of sites under positive selection on the foreground branch. So, to detect positive selection on sexual and PTH lineages we ran two branch-sites models, each with the alternative genetic system (sexual vs. PTH) in the foreground (table 1, test 4 and 5) (Yang and Nielsen 2002; Zhang et al. 2005). Finally, a clade model (Bielawski and Yang 2004) was performed to test for divergent evolution between sexual and PTH lineages; a contrast between the null model (M2a_ref) and the alternative model $(\mathrm{CmC})$ is indicative of such divergent patterns of evolution (Weadick and Chang 2012). In all cases, a likelihood ratio test (LRT) was used to assess whether contrasting nested models were statistically different from one another.

\section{Statistical analyses}

To perform statistical analyses on the signature of selection detected by PAML on defensive and non-defensive genes (defense $=721$; non-defense: 1,710 ; see table $S 1$ ), we removed orthologs with $\omega \geq 10$ since such high values could reflect very low synonymous substitutions rather than high fixation rates of nonsynonymous mutations. Filtering these values lead to some differences in the number of replicates among tests reported in table 1 (e.g., 1969 replicates in test 1 vs. 1919 replicates in test 2).

To assess how common a particular pattern of selection was, and if these frequencies were related to gene function, we used the $P$-values from LRTs that contrasted alternative PAML models (described above). These $P$-values were adjusted according to the falsediscovery rate (FDR) correction method of Benjamini and Hochberg (1995). These FDRs were estimated for detecting selective heterogeneity (site model; table 1, test 1), positive selection at the site level (site model; tests 2, 4, and 5), differences in the overall signature of selection between sexual and PTH reproductive modes (branch model; test 3), contrasting positive selection between genetic system due to gene function (branch-site model; tests 4 
720

721

and 5), and divergent evolution (clade model; test 6). To assess differences in the frequency of significant positive selection between defense and non-defensive genes, we performed $\chi^{2}$ tests-of-independence according to gene function (see table 1 independence test column and interpretation).

The overall magnitude of selection was estimated using the one-ratio model, which effectively averages dN/dS variation among all sites and branches. More complex models were used to separate the signatures of positive selection, purifying selection and neutral evolution, and to estimate the proportion of sites under each specific pattern of selection. To assess the importance of genetic system (sexual versus PTH) and gene function (defense versus non-defense) on the magnitude of positive selection $(\omega>1)$, we used the MannWhitney $U$ non-parametric test due to the non-normal distribution of $\omega$. Particularly, a randomized anova test based on 1000 iterations was performed to assess differences between defense and non-defensive genes in the proportion of sites per gene under positive selection estimated by the site model M2a. To explore if the interaction between the genetic system and gene function affected the magnitude of selection we implemented the ScheirerRay-Hare (SRH) extension of the Kruskal-Wallis test (Sokal and Rohlf 1995), by ranking the data, performing a two-way ANOVA including the interaction, and testing the ratio $H$ (computed as $S S / M S_{\text {total }}$ ) as a $\chi^{2}$ variable. The same statistical tests were performed when the proportion of sites were the dependent variable. All statistical analyses were performed using R (R Core Team 2017).

\section{Gene Ontology Analyses}

For each defense gene detected under positive selection, according to the branch-site and clade models, we describe their defensive function based on published information reported 
744 in Uniprot (see table S5). However, because defense genes can also be related to other non-

745 defensive functions, we included a complementary analysis that explored enriched functions

746 based on gene ontology annotations (Ashburner et al. 2000). Functional enrichment for

747 biological processes was calculated in $\mathrm{R}$ with the Bioconductor package topGO by performing

748 the default algorithm and the Fisher's exact test (Alexa and Rahnenfuhrer 2007). The gene

749 pool against which to compare defensive genes detected under positive selection and

750 divergent evolution was the complete set of defensive genes.

752 Acknowledgements

753 We thank Gane Ka-Shu Wong for leading the 1KP project that generated much of the raw

754 data. DC was funded by a postdoctoral fellowship from CONACyT (Consejo Nacional de

755 Ciencia y Tecnología). RWN received funding from an NSERC Discovery Grant and CFI. SIW

756 and MTJJ received funding from NSERC Discovery grants and an NSERC Accelerator sup-

757 plements, SG from the Max Planck Society and the Deutsche Forschungsgemeinschaft

758 (DFG).

759

760

761 


\section{References}

767 Adler LS, Seifert MG, Wink M, Morse GE. 2012. Reliance on pollinators predicts defensive models with diploid hosts. Evolution 63: 2131-2141. drolyzing $\beta$-glucosidase in roots of Arabidopsis. Plant Cell Physiol 51: 132-143.

2.

Anisimova M, Bielawski JP, Yang Z. 2001. Accuracy and power of the likelihood ratio test in detecting adaptive molecular evolution. Mol Biol Evol 18: 1585-1592.

Anisimova M, Nielsen R, Yang Z. 2003. Effect of recombination on the accuracy of the likelihood method for detecting positive selection at amino acid sites. Genetics 164: $1229-1236$.

Ashburner M, Ball CA, Blake JA, Botstein D, Butler H, Cherry JM, Davis AP, Dolinski K, Dwight SS, Eppig JT, et al. 2000. Gene ontology: tool for the unification of biology. Nat Genet 25: 25-29.

Bakewell MA, Shi P, Zhang J. 2007. More genes underwent positive selection in chimpanzee evolution than in human evolution. Proc Natl Acad Sci U S A 104: 7489-7494. 
Bakker EG. 2006. A genome-wide survey of $\mathrm{R}$ gene polymorphisms in Arabidopsis. The Plant Cell 18: 1803-135:18.

Barrier M, Bustamante CD, Yu J, Purugganan MD. 2003. Selection on rapidly evolving proteins in the Arabidopsis genome. Genetics 163: 723-733.

Benjamini Y, Hochberg Y. 1995. Controlling the false discovery rate: a practical and powerful approach to multiple testing. J R Stat Soc Ser B 57: 289-300.

Bergelson J, Dwyer G, Emerson JJ. 2001a. Models and data on plant-enemy coevolution. Annu Rev Genet 35: 469-499.

Bergelson J, Kreitman M, Stahl EA, Tian D. 2001b. Evolutionary dynamics of plant R-genes. Science 292: 2281-2285.

Bielawski J, Yang Z. 2004. A Maximum likelihood method for detecting functional divergence at individual codon sites, with application to gene family evolution. J Mol Evol 59: 121132.

Bielawski JP, Yang Z. 2005. Maximum likelihood methods for detecting adaptive protein evolution. In Statistical methods in molecular evolution, pp. 103-124. Springer, New York, USA.

Bishop JG, Dean AM, Mitchell-Olds T. 2000. Rapid evolution in plant chitinases: molecular targets of selection in plant-pathogen coevolution. Proc Natl Acad Sci U S A 97: 53225327.

Bomblies K, Lempe J, Epple P, Warthmann N, Lanz C, Dangl JL, Weigel D. 2007. Autoimmune response as a mechanism for a Dobzhansky-Muller-type incompatibility syndrome in plants. PLOS Biol 5: 1962-1972.

Busch JW, Neiman M, Koslow JM. 2004. Evidence for maintenance of sex by pathogens in plants. Evolution 58: 2584-2590.

Caicedo AL, Schaal BA. 2004. Heterogeneous evolutionary processes affect R gene diversity 
in natural populations of Solanum pimpinellifolium. Proc Natl Acad Sci U S A 101: 17444-17449.

Campbell SA. 2014. Ecological mechanisms for the coevolution of mating systems and defence. New Phytol 205: 1047-1053.

Campbell SA, Thaler JS, Kessler A. 2013. Plant chemistry underlies herbivore-mediated inbreeding depression in nature. Ecol Lett 16: 252-260.

Campbell SA, Kessler A. 2013. Plant mating system transitions drive the macroevolution of defense strategies. Proc Natl Acad Sci U S A 110: 3973-3978.

Carr DE, Eubanks MD. 2014. Interactions between insect herbivores and plant mating systems. Annu Rev Entomol 59: 185-203.

Carmona D, Lajeunesse MJ, Johnson MTJ. 2011. Plant traits that predict resistance to herbivores. Funct Ecol 25: 358-367.

Carretero-Paulet L, Chang T-H, Librado P, Ibarra-Laclette E, Herrera-Estrella L, Rozas J, Albert VA. 2015. Genome-wide analysis of adaptive molecular evolution in the carnivorous plant Utricularia gibba. Genome Biol Evol 7: 444-456.

Carroll SB. 2008. Evo-devo and an expanding evolutionary synthesis: a genetic theory of morphological evolution. Cell 134: 25-36.

Chen Q, Han Z, Jiang H, Tian D, Yang S. 2010. Strong positive selection drives rapid diversification of R-Genes in arabidopsis relatives. J Mol Evol 70: 137-148.

Cleland R. 1972. Oenothera: cytogenetics and evolution. Academic Press. New York, USA. Coley PD, Bryant JP, Chapin FS. 1985. Resource availability and plant antiherbivore defense. Adv Sci 230: 895-899.

Cutter AD, Wasmuth JD, Washington NL. 2008. Patterns of molecular evolution in Caenorhabditis preclude ancient origins of selfing. Genetics 178: 2093-2104. 
839

840

841

842

843

844

845

846

847

848

849

850

851

852

853

854

855

856

857

858

859

860

861

862

863

Czarnecka E, Verner FL, Gurley WB. 2012. A strategy for building an amplified transcriptional switch to detect bacterial contamination of plants. Plant Mol Biol 78: 59-75.

De Meaux J, Mitchell-Olds T. 2003. Evolution of plant resistance at the molecular level: ecological context of species interactions. Heredity 91: 345-352.

Dieckmann U, Doebeli MO. 1999. On the origin of species by sympatric speciation. Nature 400: 354-357.

Dóczi R, Brader G, Pettkó-Szandtner A, Rajh I, Djamei A, Pitzschke A, Teige M, Hirt H. 2007. The Arabidopsis mitogen-activated protein kinase kinase MKK3 is upstream of group c mitogen-activated protein kinases and participates in pathogen signaling. The Plant Cell 19: 3266-3279.

Edgar RC. 2004. MUSCLE: Multiple sequence alignment with high accuracy and high throughput. Nucleic Acids Res 32: 1792-1797.

Ehrlich PR, Raven PH. 1964. Butterflies and plants: a study in coevolution. Evolution 18: $586-608$.

Emms DM, Kelly S. 2015. OrthoFinder: solving fundamental biases in whole genome comparisons dramatically improves orthogroup inference accuracy. Genome Biol 16: 157.

Endara MJ, Coley PD. 2011. The resource availability hypothesis revisited: a meta-analysis. Funct Ecol 25: 389-398.

Endo T, Ikeo K, Gojobori T. 1996. Large-scale search for genes on which positive selection may operate. Mol Biol Evol 13: 685-690.

Eanes WF. 2011. Molecular population genetics and selection in the glycolytic pathway. J Exp Biol 214: 165-171.

Feeny P. 1976. Plant apparency and chemical defense. In Biochemical interaction between plants and insects, pp. 1-40. Springer, USA.

Felsenstein J. 1974. The evolutionary advantage of recombination. Genetics 83: 845-859. 
864

865

866

867

868

869

870

871

872

873

874

875

876

877

878

879

880

881

882

883

884

885

886

887

888

Fisher RA. 1930. The genetical theory of natural selection. Oxford University Press, Oxford, UK.

Flowers JM, Sezgin E, Kumagai S, Duvernell DD, Matzkin LM, Schmidt PS, Eanes WF. 2007. Adaptive evolution of metabolic pathways in Drosophila. Mol Biol Evol 24: 1347-1354. Frye CA. 2001. Negative regulation of defense responses in plants by a conserved MAPKK kinase. Proc Natl Acad Sci U S A 98: 373-378.

Fumagalli M, Moltke I, Grarup N, Racimo F, Bjerregaard P, Jørgensen ME, Korneliussen TS, Gerbault P, Skotte L, Linneberg A, et al. 2015. Greenlandic Inuit show genetic signatures of diet and climate adaptation. Science 349: 1343-1347.

Gabriel W, Lynch M, Burger R. 1993. Muller's ratchet and mutational meltdowns. Evolution 47: 1744-1757.

Gao M, Liu J, Bi D, Zhang Z, Cheng F, Chen S, Zhang Y. 2008. MEKK1, MKK1/MKK2 and MPK4 function together in a mitogen-activated protein kinase cascade to regulate innate immunity in plants. Cell Res 18: 1190-1198.

Golczyk H, Massouh A, Greiner S. 2014. Translocations of chromosome end-segments and facultative heterochromatin promote meiotic ring formation in evening primroses. Plant Cell 26: 1280-1293.

Gomulkiewicz R, Thompson JN, Holt RD, Nuismer SL, Hochberg ME. 2000. hot spots, cold spots, and the geographic mosaic theory of coevolution. Am Nat 156: 156-174.

Gos G, Slotte T, Wright SI. 2012. Signatures of balancing selection are maintained at disease resistance loci following mating system evolution and a population bottleneck in the genus Capsella. Mol Biol Evol 12: 152, doi: 10.1186/1471-2148-12-152.

Gray JC, Goddard MR. 2012. Sex enhances adaptation by unlinking beneficial from detrimental mutations in experimental yeast populations. BMC Evol Biol 12: 43, doi: 10.1186/1471-2148-12-43. 
889

890

891

892

893

894

895

896

897

898

899

900

901

902

903

904

905

906

907

908

909

910

911

Hartfield M. 2015. Evolutionary genetic consequences of facultative sex and outcrossing. J

Evol Biol 29: 5-22.

Hartfield M, Keightley PD. 2012. Current hypotheses for the evolution of sex and recombination. Integr Zool 7: 192-209.

Haudry A, Cenci A, Guilhaumon C, Paux E, Poirier S, Santoni S, É L. 2008. Mating system and recombination affect molecular evolution in four Triticeae species. Genet Res Camb 90: 97-109.

Hawkes C V, Sullivan JJ. 2010. The impact of herbivory on plants in different resource conditions : a meta-analysis. Ecology 82: 2045-2058.

Henry L, Schwander T, Crespi BJ. 2012. Deleterious mutation accumulation in asexual timema stick insects. Mol Biol Evol 29: 401-408.

Herms D a., Mattson WJ. 1992. The dilemma of plants: to grow or defend. Q Rev Biol 67: $283-335$.

Hersch-Green El, Myburg H, Johnson MTJ. 2012. Adaptive molecular evolution of a defence gene in sexual but not functionally asexual evening primroses. J Evol Biol 25: 15761586.

Hoekstra HE, Coyne JA. 2007. The locus of evolution: Evo devo and the genetics of adaptation. Evolution 61: 995-1016.

Hollister JD, Greiner S, Wang W, Wang J, Zhang Y, Wong GK-S, Wright SI, Johnson MTJ. 2015. Recurrent loss of sex is associated with accumulation of deleterious mutations in Oenothera. Mol Biol Evol 32: 896-905.

Hughes AL. 2007. Looking for Darwin in all the wrong places: The misguided quest for positive selection at the nucleotide sequence level. Heredity 99: 364-373. 
Hussin JG, Hodgkinson A, Idaghdour Y, Grenier JC, Goulet JP, Gbeha E, Hip-Ki E, Awadalla P. 2015. Recombination affects accumulation of damaging and disease-associated mutations in human populations. Nat Genet 47: 400-404.

Johnson MTJ, Campbell SA, Barrett SCH. 2015. Evolutionary interactions between plant reproduction and defense against herbivores. Annu Rev Ecol Evol Syst 46: 191-213.

Johnson MTJ, Carpenter EJ, Tian Z, Bruskiewich R, Burris JN, Carrigan CT, Chase MW, Clarke ND, Covshoff S, Depamphilis CW, et al. 2012. Evaluating methods for isolating total RNA and predicting the success of sequencing phylogenetically diverse plant transcriptomes. PLoS One 7: e50226, doi: 10.1371/journal.pone.0050226.

Johnson MTJ, Ives AR, Ahern J, Salminen JP. 2014. Macroevolution of plant defenses against herbivores in the evening primroses. New Phytol 203: 267-279.

Johnson MTJ, Smith SD, Rausher MD. 2009. Plant sex and the evolution of plant defenses against herbivores. Proc Natl Acad Sci U S A 106: 18079-18084.

Karasov TL, Horton MW, Bergelson J. 2014. Genomic variability as a driver of plant-pathogen coevolution? Curr Opin Plant Biol 18: 24-30.

Kidd BN, Edgar Cl, Kumar KK, Aitken EA, Schenk PM, Manners JM, Kazan K. 2009. The mediator complex subunit PFT1 is a key regulator of jasmonate-dependent defense in Arabidopsis. The Plant Cell 21: 2237-2252.

Kondrashov AS. 1988. Deleterious mutations and the evolution of sexual reproduction. Nature 336:435-440.

Kryazhimskiy S, Plotkin JB. 2008. The population genetics of dN/dS. PLoS Genet 4: e1000304, doi:10.1371/journal.pgen.1000304.

Lamichhaney S, Berglund J, Almén MS, Maqbool K, Grabherr M, Martinez-Barrio A, Promerová M, Rubin CJ, Wang C, Zamani N, et al. 2015. Evolution of Darwin's finches and their beaks revealed by genome sequencing. Nature 518: 371-375. 
937

938

939

940

941

942

943

944

945

946

947

948

949

950

951

952

953

954

955

956

957

958

959

960

961

Levin DA. 1975. Pest pressure and recombination systems in plants. Am Nat 109: 437-451.

Li W-H, Wu C-I, Luo C-C. 1985. A new method for estimating synonymous and nonsynonymous rate of nucleotide substitution considering the relative likelihood of nucleotide and codon changes. Molecular 2: 150-174.

Lively CM. 2010. A review of red queen models for the persistence of obligate sexual reproduction. J Hered 101: 13-20.

Lively CM, Morran LT. 2014. The ecology of sexual reproduction. J Evol Biol 27: 1292-1303. Lovell JT, Williamson RJ, Wright SI, McKay JK, Sharbel TF. 2017. Mutation accumulation in an asexual relative of Arabidopsis. PLoS Genet 13: e1006550, doi:10.1371/journal. pgen.1006550.

Lu X, Tintor N, Mentzel T, Kombrink E, Boller T, Robatzek S, Schulze-Lefert P, Saijo Y. 2009. Uncoupling of sustained MAMP receptor signaling from early outputs in an Arabidopsis endoplasmic reticulum glucosidase II allele. Proc Natl Acad Sci U S A 106: 2252222527.

Matasci N, Hung LH, Yan Z, Carpenter EJ, Wickett NJ, Mirarab S, Nguyen N, Warnow T, Ayyampalayam S, Barker M, et al. 2014. Data access for the 1,000 Plants (1KP) project. Gigascience 3: 17, doi: 10.1186/2047-217X-3-17.

Mauricio R, Rausher MD. 1997. Experimental manipulation of putative selective agents provides evidence for the role of natural enemies in the evolution of plant defense. Evolution 51: 1435-1444.

Mauricio R, Stahl EA, Korves T, Tian D, Kreitman M, Bergelson J. 2003. Natural selection for polymorphism in the disease resistance gene Rps2 of Arabidopsis thaliana. Genetics 163: $735-746$.

McDonald, JH, Kreitman M. 1991. Adaptive protein evolution at the Adh locus in Drosophila. Nature 351: 652-654. 
962

963

964

965

966

967

968

969

970

971

972

973

974

975

976

977

978

979

980

981

982

983

984

McDonald MJ, Rice DP, Desai MM. 2016. Sex speeds adaptation by altering the dynamics of molecular evolution. Nature 531: 233-236.

Meyers BC. 1998. Receptor-like genes in the major resistance locus of lettuce are subject to divergent selection. The Plant Cell 10: 1833-1846.

Meyers BC, Kaushik S, Nandety RS. 2005. Evolving disease resistance genes. Curr Opin Plant Biol 8: 129-134.

Michelmore RW, Meyers BC, Young ND. 1998. Cluster of resistance genes in plants evolveby divergent selection and a birth-and-death process. Curr Opin Plant Biol 3: 285-290.

Mondragón-Palomino M, Meyers BC, Michelmore RW, Gaut BS. 2002. Patterns of positive selection in the complete NBS-LRR gene family of Arabidopsis thaliana. Genome Res 12: $1305-1315$.

Muller HJ. 1932. Some genetic aspects of Sex. Am Nat 66: 118-138.

Muller HJ. 1964. The relation of recombination to mutational advance. Mutat Res Mol Mech Mutagen 1: 2-9.

Navarro L, Dunoyer P, Jay F, Arnold B, Dharmasiri N, Estelle M, Voinnet O, Jones JDG. 2006. A plant miRNA contributes to antibacterial resistance by repressing auxin signaling. Science 312: 436-439.

Nei M, Gojobori T. 1986. Simple methods for estimating the numbers of synonymous and nonsynonymous nucleotide substitutions. Mol Biol Evol 3: 418-426.

Neiman M, Lively CM, Meirmans S. 2017. Why sex? A pluralist approach revisited. Trends Ecol Evol 32: 589-600.

Nielsen R, Yang Z. 1998. Likelihood models for detecting positively selected amino acid sites and applications to the HIV-1 envelope gene. Genetics 148: 929-936. 
Nishikiori M, Mori M, Dohi K, Okamura H, Katoh E, Naito S, Meshi T, Ishikawa M. 2011. A host small GTP-binding protein ARL8 plays crucial roles in tobamovirus RNA replication. PLoS Pathog 7: e1002409, doi:10.1371/journal.ppat.1002409.

Nuismer SL, Thompson JN, Gomulkiewicz R. 1999. Gene flow and geographically structured coevolution. Proc R Soc B Biol Sci 266: 605-609.

Ollivier M, Gabaldón T, Poulain J, Gavory F, Leterme N, Gauthier JP, Legeai F, Tagu D, Simon JC, Rispe C. 2012. Comparison of gene repertoires and patterns of evolutionary rates in eight aphid species that differ by reproductive mode. Genome Biol Evol 4: 155-167.

Otto SP, Nuismer SL. 2004. Species interactions and the evolution of sex. Science 304: 1018-1020.

Payne BL, Alvarez-Ponce D. 2018. Higher rates of protein evolution in the self-fertilizing plant Arabidopsis thaliana than in the out-crossers Arabidopsis lyrata and Arabidopsis halleri. Genome Biol Evol 10: 895-900.

Prasad KVSK, Song BH, Olson-Manning C, Anderson J.T, Lee CR, Schranz ME, Windsor AJ, Clauss MJ, Manzaneda AJ, Naqvi I, etc. 2012. A gain-of-function polymorphism controlling complex traits and fitness in nature. Science 337: 1081-1084.

Ramsay H, Rieseberg LH, Ritland K. 2009. The correlation of evolutionary rate with pathway position in plant terpenoid biosynthesis. Mol Biol Evol 26: 1045-1053.

Ranganath RM. 2008. Meiotic chromosome pairing and recombination take refuge in the telomeres. Nat Rev Genet 9: 318, doi: 10.1038/nrg2224-c1.

Rausher MD. 2008. Evolutionary transitions in floral color. Int J Plant Sci 169: 7-21.

Rausher MD, Miller RE, Tiffin P. 1999. Patterns of evolutionary rate variation among genes of the anthocyanin biosynthetic pathway. Mol Biol Evol 16: 266-274.

Rausher MD, Huang J. 2015. Prolonged adaptive evolution of a defensive gene in the solanaceae. Mol Biol Evol 33: 143-151. 
1010

1011

1012

1013

1014

1015

1016

1017

1018

1019

1020

1021

1022

1023

1024

1025

1026

1027

1028

1029

1030

1031

1032

1033

1034

Rauwolf U, Golczyk H, Meurer J, Herrmann RG, Greiner S. 2008. Molecular marker systems for oenothera genetics. Genetics 180: 1289-1306.

Rauwolf U, Greiner S, Mráek J, Rauwolf M, Golczyk H, Mohler V, Herrmann RG, Meurer J. 2011. Uncoupling of sexual reproduction from homologous recombination in homozygous Oenothera species. Heredity 107: 87-94.

Rose LE, Bittner-Eddy PD, Langley CH, Holub EB, Michelmore RW, Beynon JL. 2004. The maintenance of extreme amino acid diversity at the disease resistance gene, $R P P 13$, in Arabidopsis thaliana. Genetics 166: 1517-1527.

Rosenthal GA, Janzen DH. 1979. Herbivores: Their interaction with secondary metabolites. Academic Press, New York, USA.

Roth C, Liberles DA. 2006. A systematic search for positive selection in higher plants (Embryophytes). BMC Plant Biol 6: 12, doi:10.1186/1471-2229-6-12.

Salathé M, Kouyos RD, Regoes RR, Bonhoeffer S. 2008. Rapid parasite adaptation drives selection for high recombination rates. Evolution 62: 295-300.

Scannell DR, Wolfe KH. 2008. A burst of protein sequence evolution and a prolonged period of asymmetric evolution follow gene duplication in yeast. Genome Res 18: 137-147.

Shapiro MD, Marks ME, Peichel CL, Blackman BK, Nereng KS, Jonsson B, Schluter D, Kingsley DM. 2004. Genetic and developmental basis of evolutionary pelvic reduction in threespine sticklebacks. Nature 428: 717-723.

Scherer NM, Thompson CE, Freitas LB, Bonatto SL, Salzano FM. 2005. Patterns of molecular evolution in pathogenesis-related proteins. Genet Mol Biol 28: 645-653.

Schmid KJ, Tautz D. 1997. A screen for fast evolving genes from Drosophila. Proc Natl Acad Sci U S A 94: 9746-9750.

Schulz MH, Zerbino DR, Vingron M, Birney E. 2012. Oases: robust de novo RNA-seq assembly across the dynamic range of expression levels. Bioinforma Orig Pap 28: 1086-1092. 
1035

1036

1037

1038

1039

1040

1041

1042

1043

1044

1045

1046

1047

1048

1049

1050

1051

1052

1053

1054

1055

1056

1057

1058

Sherameti I, Tripathi S, Varma A, Oelmüller R. 2008. The root-colonizing endophyte pirifomospora indica confers drought tolerance in Arabidopsis by stimulating the expression of drought stress-related genes in leaves. Mol Plant-Microbe Interact 21: 799-807.

Sicard A, Kappel C, Josephs EB, Lee YW, Marona C, Stinchcombe JR, Wright SI, Lenhard M. 2015. Divergent sorting of a balanced ancestral polymorphism underlies the establishment of gene-flow barriers in Capsella. Nat Commun 6: 7960, doi: 10.1038/ncomms8960.

Sokal RR, Rohlf FJ. 1995. Biometry: the principles and practice of statistics in biological research, 3rd ed. WH Freeman, New York, USA.

Stahl EA, Dwyer G, Mauricio R, Kreitman M, Bergelson J. 1999. Dynamics of disease resistance polymorpism at the Rpm 1 locus of Arabidopis. Nature 400: 667-671.

Stamatakis A. 2006. RAxML-VI-HPC: Maximum likelihood-based phylogenetic analyses with thousands of taxa and mixed models. Bioinformatics 22: 2688-2690.

Strauss SY, Cacho NI, Schwartz MW, Schwartz AC, Burns KC. 2015. Apparency revisited. Entomol Exp Appl 157: 74-85.

Talyzina NM, Ingvarsson PK. 2006. Molecular evolution of a small gene family of wound inducible Kunitz trypsin inhibitors in Populus. J Mol Evol 63: 108-119.

Tian D, Araki H, Stahl E, Bergelson J, Kreitman M. 2002. Signature of balancing selection in Arabidopsis. Science 99: 11525-11530.

Tiffin P, Hahn MW. 2002. Coding sequence divergence between two closely related plant species: Arabidopsis thaliana and Brassica rapa ssp. pekinensis. J Mol Evol 54: 746753.

Tiffin P, Moeller DA. 2006. Molecular evolution of plant immune system genes. Trends Genet 22: $662-670$. 
1059

1060

1061

1062

1063

1064

1065

1066

1067

1068

1069

1070

1071

1072

1073

1074

1075

1076

1077

1078

1079

1080

1081

1082

Tucker AE, Ackerman MS, Eads BD, Xu S, Lynch M. 2013. Population-genomic insights into the evolutionary origin and fate of obligately asexual Daphnia pulex. Proc Natl Acad Sci U S A 110: 15740-15745.

Turcotte MM, Davies TJ, Thomsen CJM, Johnson MTJ, B PRS. 2014. Macroecological and macroevolutionary patterns of leaf herbivory across vascular plants. Proc $R$ Soc $B$ Biol Sci 281: 1-7.

Vellosillo T, Martinez M, Lopez MA, Vicente J, Cascon T, Dolan L, Hamberg M, Castresana C. 2007. Oxylipins produced by the 9-lipoxygenase pathway in Arabidopsis regulate lateral root development and defense responses through a specific signaling cascade. The Plant Cell 19: 831-846.

Wagner WL, Hoch PC, Raven PH. 2007. Revised classification of the Onagraceae. Syst Bot Monogr 83: 1-222

Wang Q, Wang M, Zhang X, Hao B, Kaushik SK, Pan Y. 2011. WRKY gene family evolution in Arabidopsis thaliana. Genetica 139: 973-983.

Weadick CJ, Chang BSW. 2012. Complex patterns of divergence among green-sensitive (RH2a) african cichlid opsins revealed by clade model analyses. BMC Evol Biol 12: 206, doi: 10.1186/1471-2148-12-206.

Weiberg A, Wang M, Bellinger M, Jin H. 2014. Small RNAs: a new paradigm in plant-microbe interactions. Annu Rev Phytopathol 52: 495-516.

Welch DBM, Meselson MS. 2001. Rates of nucleotide substitution in sexual and anciently asexual rotifers. Proc Natl Acad Sci U S A 98: 6720-6724.

Wiermer M, Cheng YT, Imkampe J, Li M, Wang D, Lipka V, Li X. 2012. Putative members of the Arabidopsis Nup107-160 nuclear pore sub-complex contribute to pathogen defense. Plant J 70: 796-808. 
1083

1084

1085

1086

1087

1088

1089

1090

1091

1092

1093

1094

1095

1096

1097

1098

1099

1100

1101

1102

1103

1104

1105

Wise MJ, Rausher MD. 2013. Evolution of resistance to a multiple-herbivore community: Genetic Correlations, diffuse coevolution, and constraints on the plant's response to selection. Evolution 67: 1767-1779.

Wray GA. 2007. The evolutionary significance of cis-regulatory mutations. Nat Rev Genet 8: 206-216.

Wright KM, Rausher MD. 2010. The evolution of control and distribution of adaptive mutations in a metabolic pathway. Genetics 184: 483-502.

Wright SI, Lauga B, Charlesworth D. 2002. Rates and patterns of molecular evolution in inbred and outbred Arabidopsis. Mol Biol Evol 19: 1407-1420.

Yang Z. 1998. Likelihood ratio tests for detecting positive selection and application to primate lysozyme evolution. Mol Biol Evol 15: 568-573.

Yang Z. 2007. PAML 4: Phylogenetic Analysis by Maximum Likelihood. Mol Biol Evol 24: 1586-1591.

Yang Z, Bielawski JR. 2000. Statistical methods for detecting molecular adaptation. Trends Ecol Evol 15: 496-503.

Yang Z, Nielsen R. 2002. Codon-substitution models for detecting molecular adaptation at individual sites along specific lineages. Mol Biol Evol 19: 908-917.

Yang Z, Nielsen R, Goldman N, Pedersen AMK. 2000. Codon-substitution models for heterogeneous selection pressure at amino acid sites. Mol Biol Evol 19: 49-57.

Yang Z, Dos Reis M. 2011. Statistical properties of the branch-site test of positive selection. Mol Biol Evol 28: 1217-1228.

Zhang J, Nielsen R, Yang Z. 2005. Evaluation of an improved branch-site likelihood method for detecting positive selection at the molecular level. Mol Biol Evol 22: 2472-2479. 
1106 Zhang X, Dai Y, Xiong Y, DeFraia C, Li J, Dong X, Mou Z. 2007. Overexpression of Arabidop-

1107 sis MAP kinase kinase 7 leads to activation of plant basal and systemic acquired resis-

$1108 \quad$ tance. Plant J 52: 1066-1079.

1109 Zhang Y. 2005. A putative nucleoporin 96 is required for both basal defense and constitutive resistance responses mediated by suppressor of npr1-1,constitutive 1. The Plant Cell 17:

1111 1306-1316.

1112

1113

1114

1115

1116

1117

1118 


\section{Supplementary Material}

1130 Table S1. Basic information describing the number of loci associated with defense and non-

Table S2. Genes detected under positive selection based on PAML site model and branch-site models. We also included a list of genes detected under divergent evolution based on clade models. Sites under positive selection in this model are defined as $\omega 2>1$, so bold text indicates genes under positive selection where $\omega 2$ showed values above 1. Genes detected under divergent evolution were highlighted when at least one clade, either sexual or PTH were under positive selection.

Table S3. GO enrichment test using genes under positive selection detected by branch-site models in PAML. See fig. S3 for a graphical representation of this result, and fig. S4 to visualize the position of the first statistically significant GO terms (in bold) in the GO hierarchy. TopGo was used to perform these analyses using the default algorithm and a Fisher exact test (Alexa et al. 2006). Only terms with a $P$-value $<0.05$. are shown.

Table S4. GO enrichment test using genes under divergent evolution detected by Clade models in PAML. See fig. S5 for a graphical representation of this result, and fig. S6 to visualize the position of the first five statistically significant GO terms (in bold) in the GO hierarchy. TopGo was used to perform these analyses using the default algorithm and a Fisher exact test (Alexa et al. 2006). Only terms with a $P$-value $<0.05$. are shown.

Table S5. Detailed description of defense genes detected under positive selection and divergent evolution. Values within parentheses indicate the proportion of sites detected under positive selection (from test 4 and 5 in table 1) or divergent evolution (from test 6 in table 1). Table S2 shows the full set of genes under positive selection and divergent evolution.

Table S6. This table provides general information that links the present work with the previous research done by Hollister et al. (2015). We report general information about the initial and final number of loci associated with defense and non-defense genes after removing polymorphic variation. We included also Hollister et al.'s (2015) list of species since some species' names were changed in our analyses (e.g., Oenothera capillifolia versus $O$. berlandieri), we also added an experimental individual (O. elata hookeri ROLB; Johansen standard), and we included new IDs that are not found in Hollister et al.'s supplementary data (Table_1S.xlsx). Text in bold indicates new ID or the inclusion of new species. Hyphen indicates that experimental individuals, replicates for a species, were collapsed at the species level after removing polymorphic sites.

\section{Figures}

FIG. S1. Proportion of amino acid sites experiencing positive selection in defense and nondefensive genes.

FIG. S2. Graphical representation of enrichment analysis for defensive genes under positive selection detected by the Branch-site model.

FIG. S3. GO structure for the first five enriched nodes detected by the enrichment test. Terms framed within a rectangle are significant and an increase in red coloration indicates higher 
1177 values of significance (i.e., lower $P$-values) in the enriched test. Zoom in to see the identity 1178 and additional information about the nodes.

1180 FIG. S4. Graphical representation of enrichment analysis for defensive genes under divergent 1181 evolution detected by clade models.

FIG. S5. GO structure for the first five enriched nodes detected by the enrichment test of genes under divergent evolution. Terms framed within a rectangle are significant and an increase in red coloration indicates higher values of significance (i.e., lower $P$-values) in the enriched test. Zoom in to see the identity and additional information about the nodes. 
Table S1. Basic information describing the number of loci associated with defense and non-

1207 defensive function at each step of the bioinformatic pipeline.

\begin{tabular}{|c|c|c|c|}
\hline & \multicolumn{2}{|c|}{ Function } & \multirow[b]{2}{*}{ Description } \\
\hline Total number of & Defense loci & Non-defensive loci & \\
\hline Annotations & 3,120 & 286,238 & \multirow{2}{*}{$\begin{array}{l}\text { Number of annotations and } \\
\text { genes with different function } \\
\text { associated to the ATH GO } \\
\text { GOSLIM file } \\
\text { (March 2016) }\end{array}$} \\
\hline Genes & 1,454 & 30,471 & \\
\hline Proteins & 1,232 & 15,011 & \multirow{2}{*}{$\begin{array}{l}\text { Number of proteins and } \\
\text { sequences downloaded from } \\
\text { Uniprot for each gene } \\
\text { function. }\end{array}$} \\
\hline $\begin{array}{l}\text { Downloaded } \\
\text { sequences of proteins }\end{array}$ & 1,232 & $\begin{array}{c}2000 \\
\text { (random sample) }\end{array}$ & \\
\hline Orthogroups & 5,649 & 13,457 & $\begin{array}{l}\text { Number of orthogroups } \\
\text { created by Orthogfinder }\end{array}$ \\
\hline Final Orthogroups & 721 & 1,710 & $\begin{array}{l}\text { Number of loci after filtering } \\
\text { The filtering process included: } \\
\text { - } \text { Removing orthogroups } \\
\text { full of paralogous. } \\
\text { - } \text { Removing bad multiple } \\
\text { sequence alignment } \\
\text { (MSA) } \\
\text { Removing Orthogroups } \\
\text { with less than } 3 \\
\text { species by genetic } \\
\text { system (sexual and } \\
\text { PTH). }\end{array}$ \\
\hline
\end{tabular}




\begin{tabular}{|c|c|c|c|}
\hline 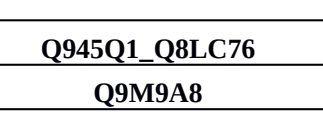 & 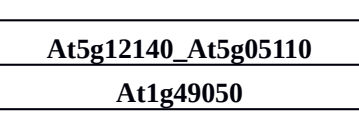 & 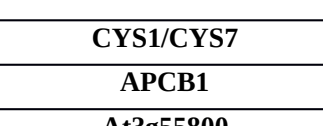 & 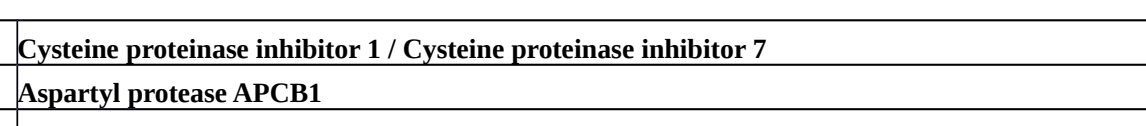 \\
\hline 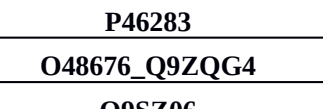 & 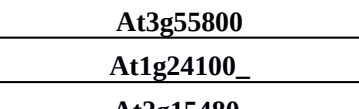 & & 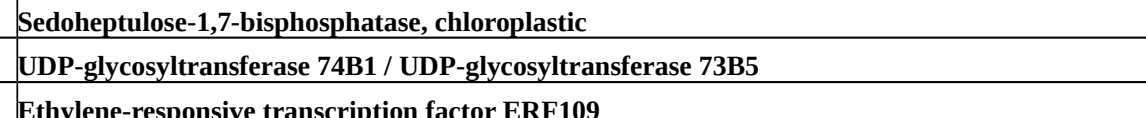 \\
\hline & 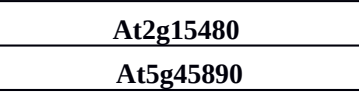 & 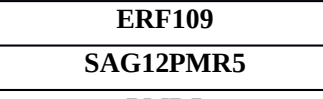 & 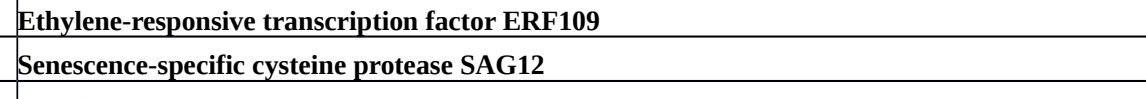 \\
\hline & 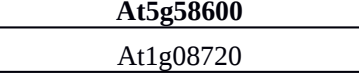 & & 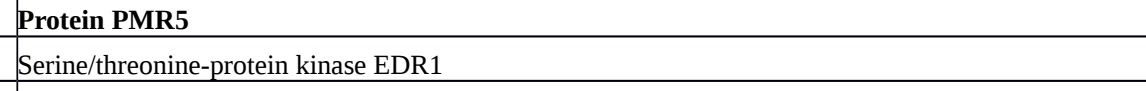 \\
\hline & 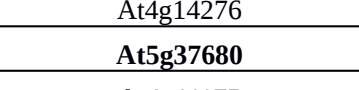 & 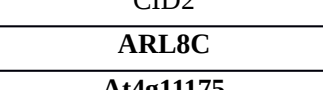 & 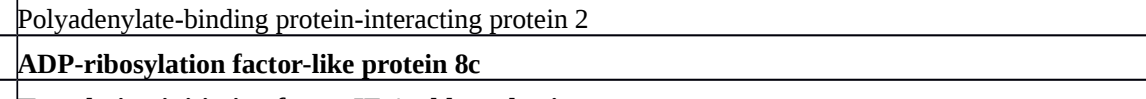 \\
\hline & 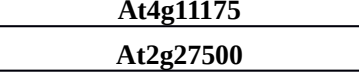 & 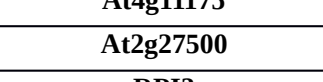 & 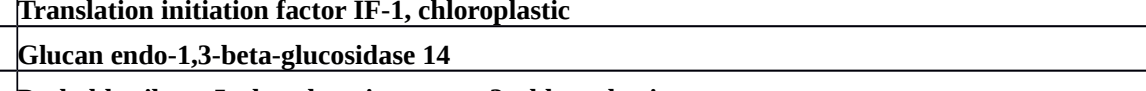 \\
\hline & & & 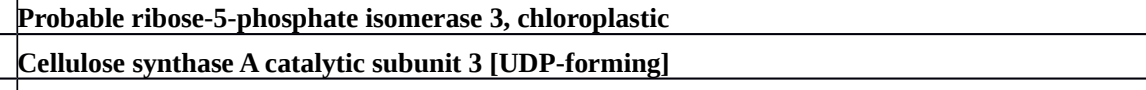 \\
\hline & & 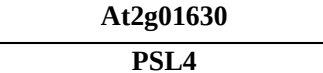 & \\
\hline 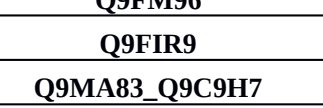 & 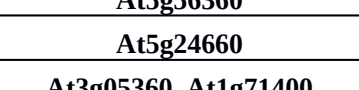 & $\frac{\mathrm{SUV2}}{\mathrm{R}}$ & 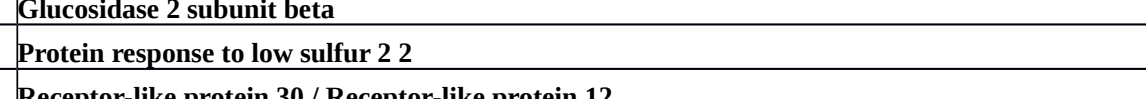 \\
\hline & 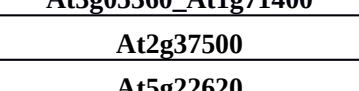 & Ant23500 & 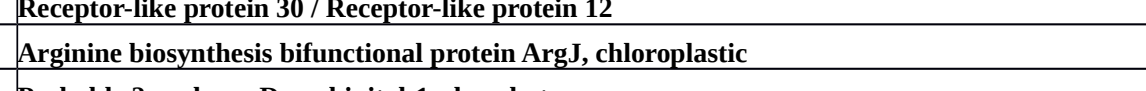 \\
\hline & & & 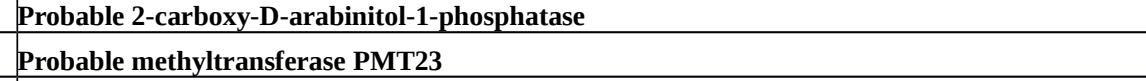 \\
\hline & 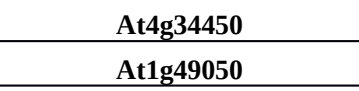 & 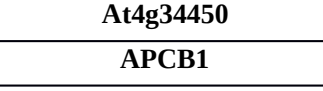 & 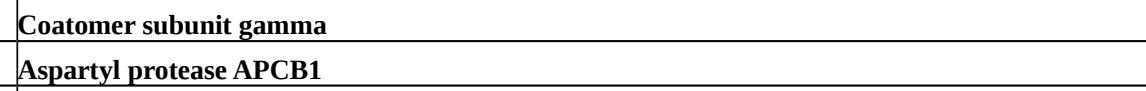 \\
\hline & 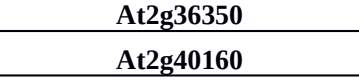 & tisto & 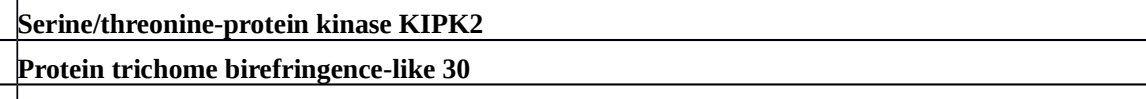 \\
\hline & & & 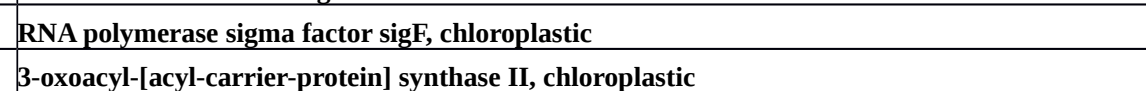 \\
\hline & & 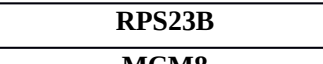 & 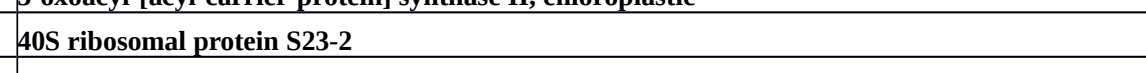 \\
\hline & 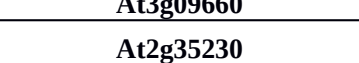 & IKU1 & 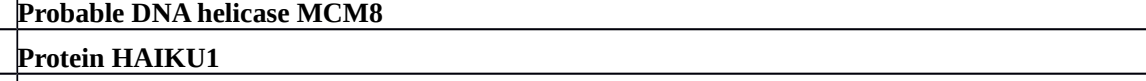 \\
\hline 7.991R7 & & Inx & 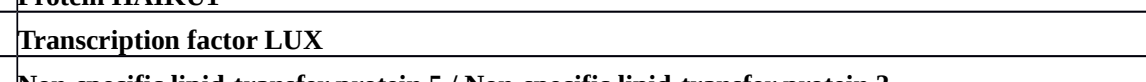 \\
\hline 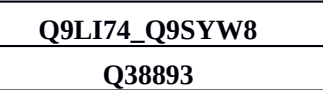 & 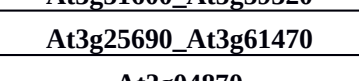 & & 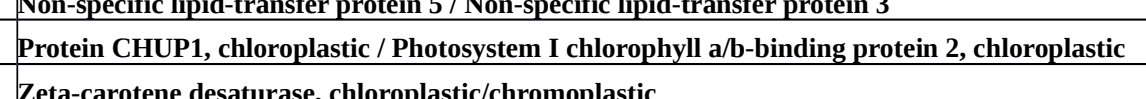 \\
\hline & 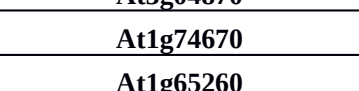 & 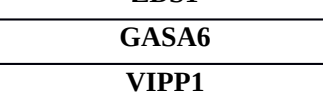 & 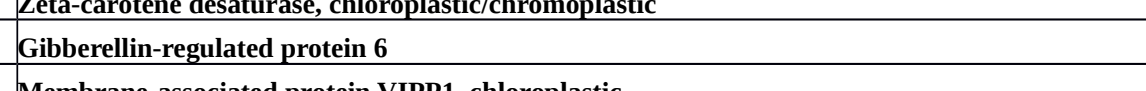 \\
\hline & & & 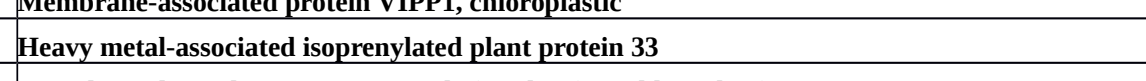 \\
\hline & & Lipro.6. & 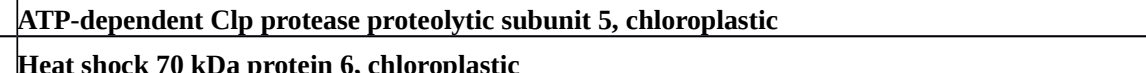 \\
\hline 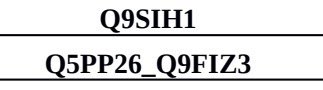 & 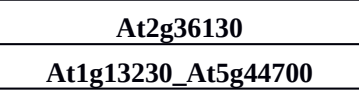 & 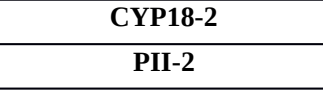 & 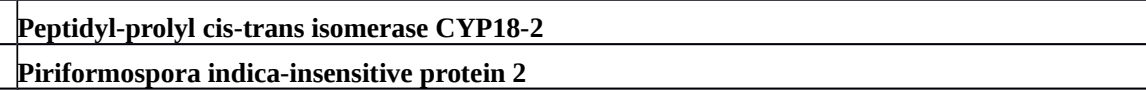 \\
\hline & & & 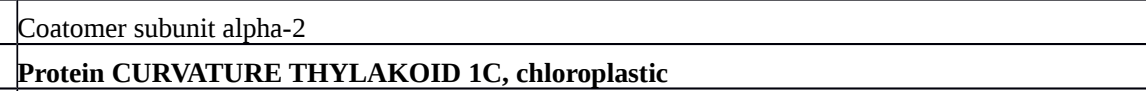 \\
\hline & Alng: & $\begin{array}{l}\mathrm{EPP} \\
\mathrm{YHS}\end{array}$ & 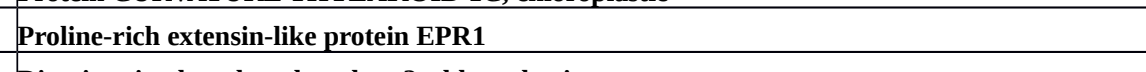 \\
\hline & & GASA5 & 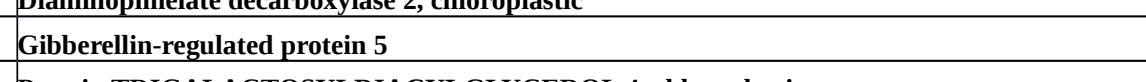 \\
\hline & & & 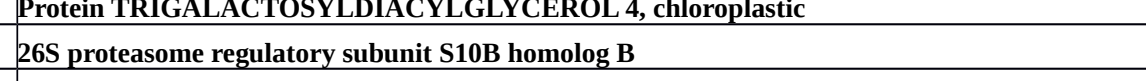 \\
\hline & & & 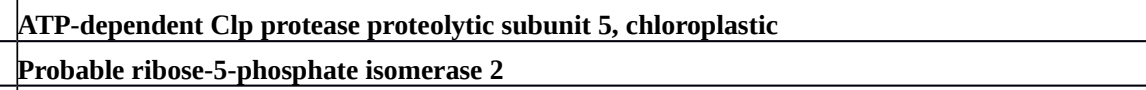 \\
\hline & & 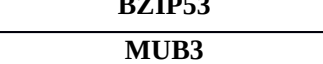 & 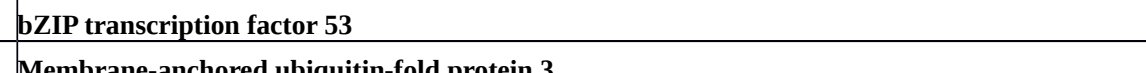 \\
\hline$=$ & 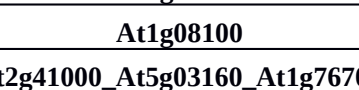 & 年 & 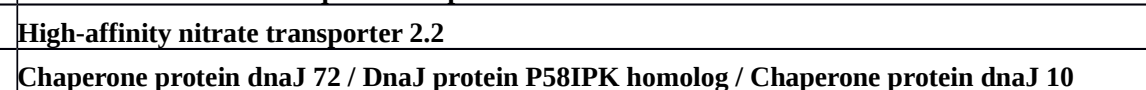 \\
\hline & 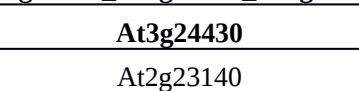 & & 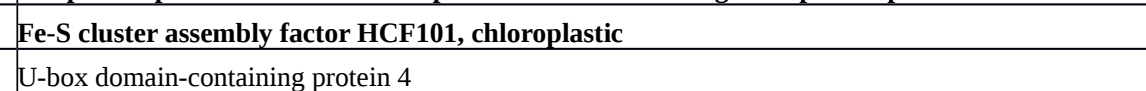 \\
\hline
\end{tabular}

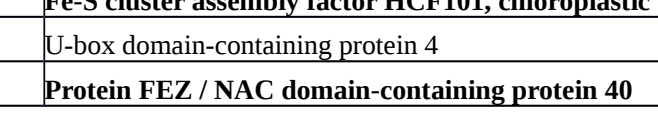

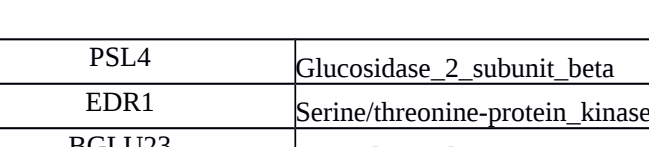

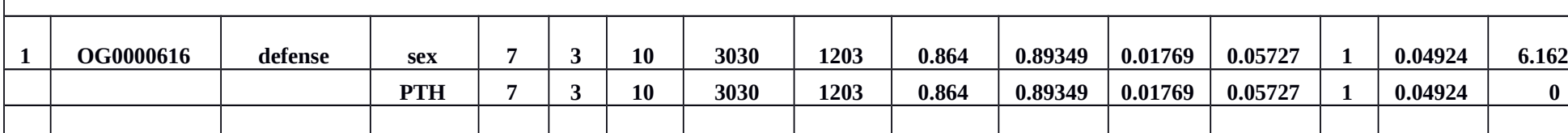

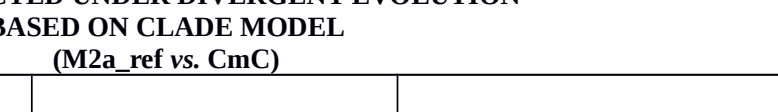

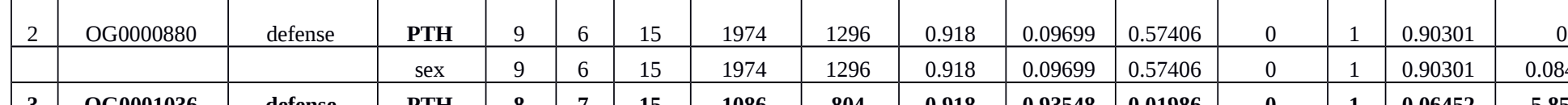

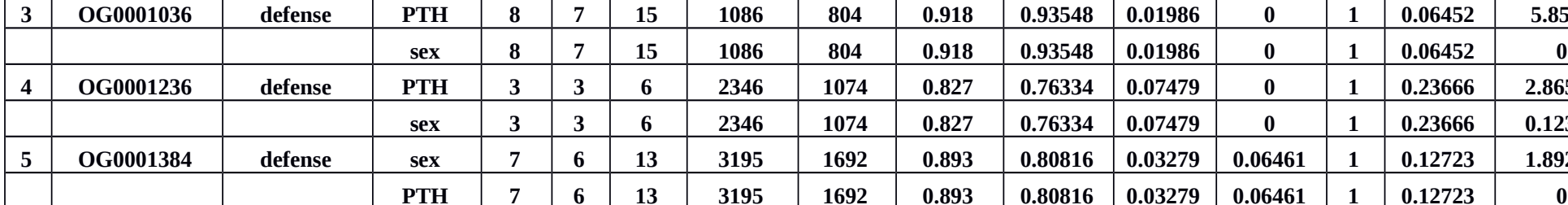

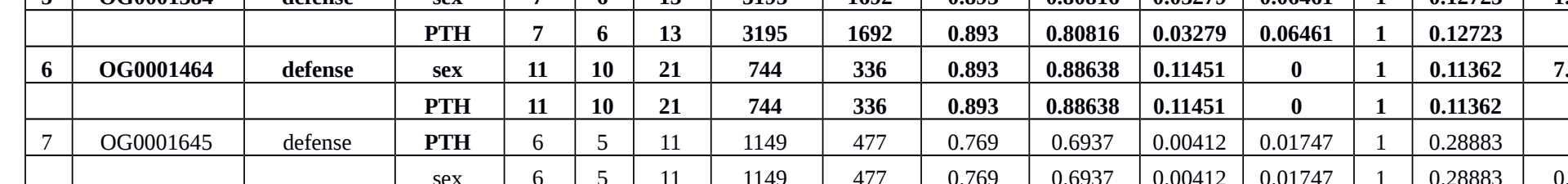

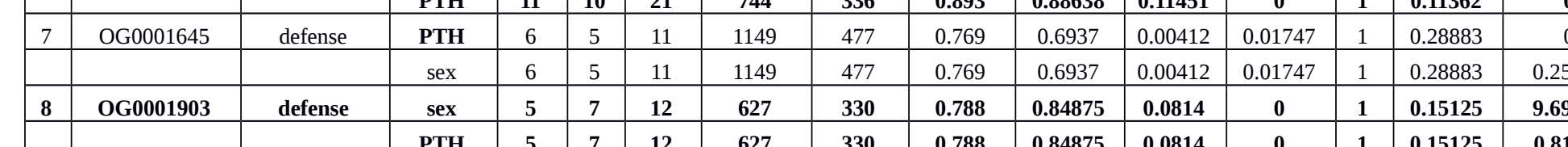

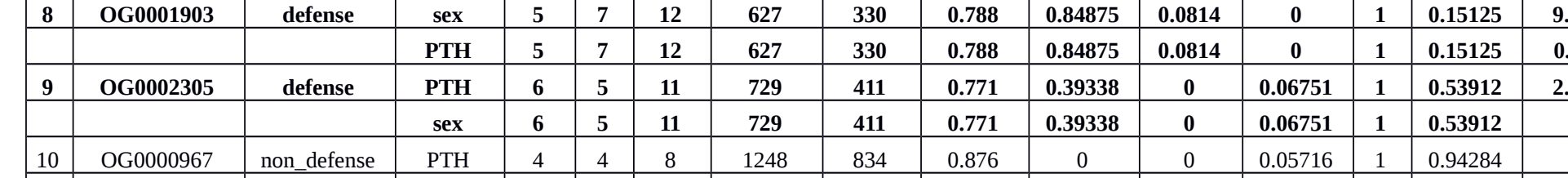

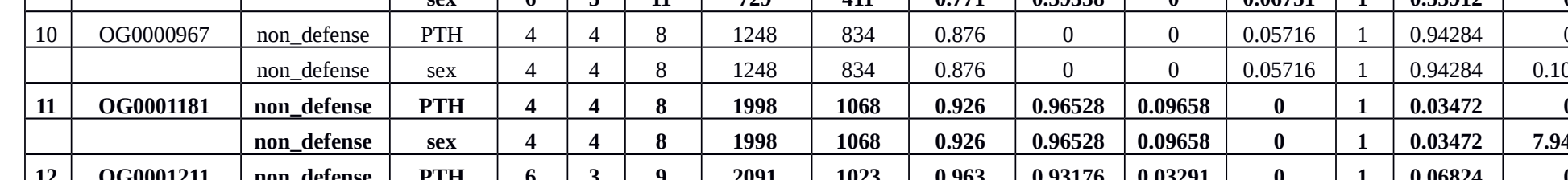

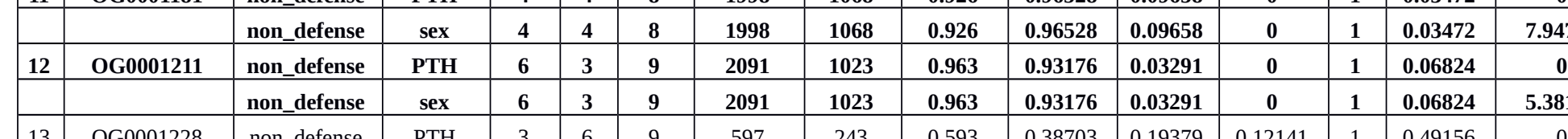

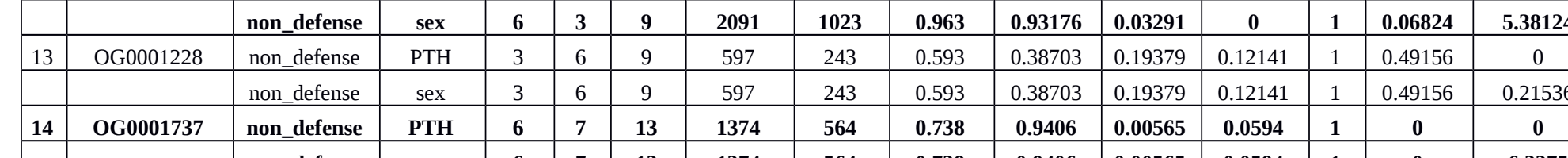

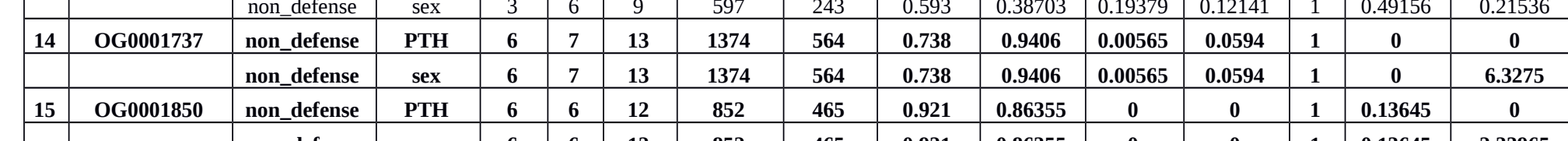

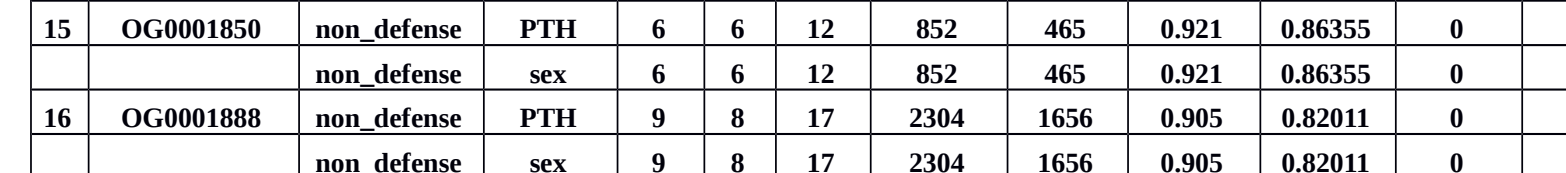

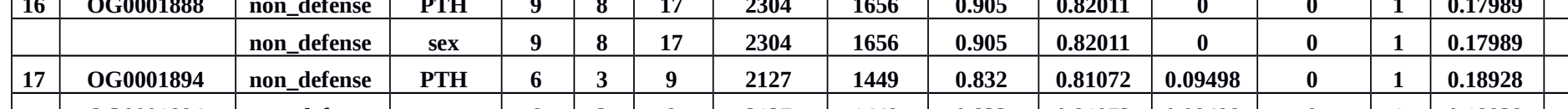

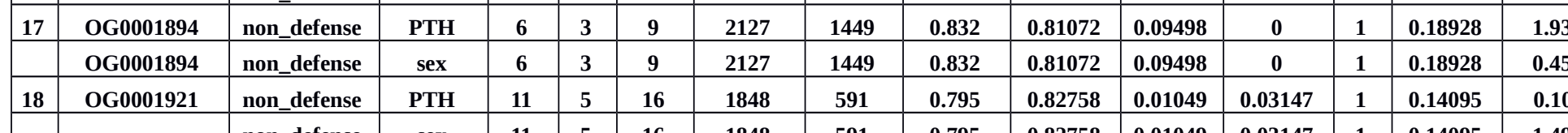

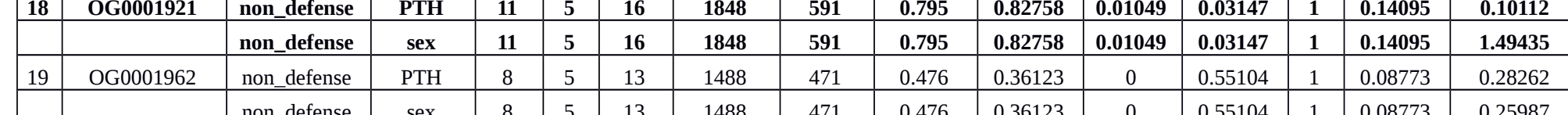

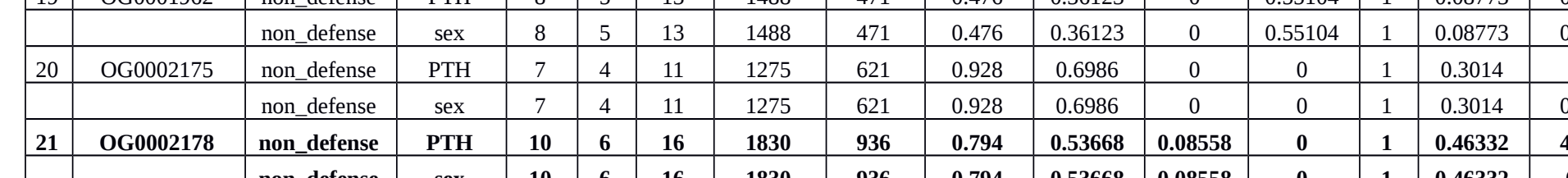

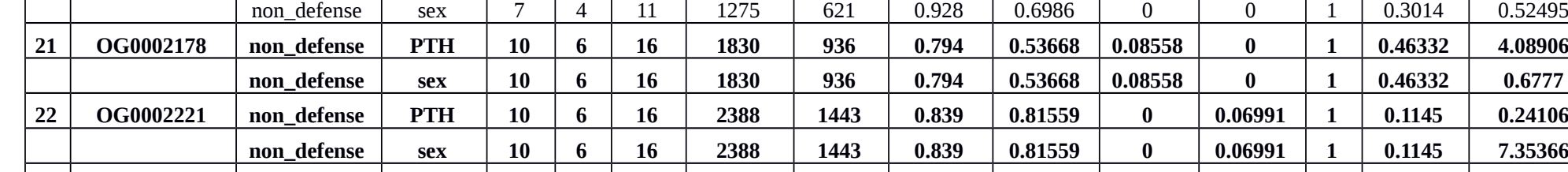

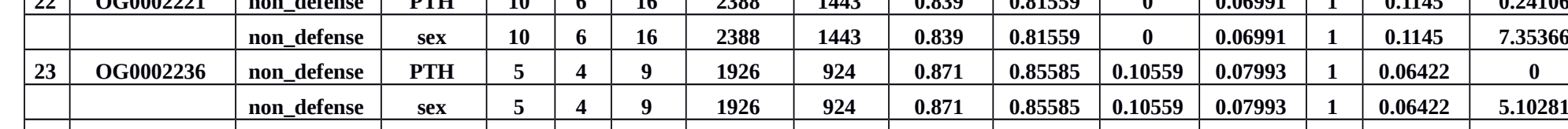

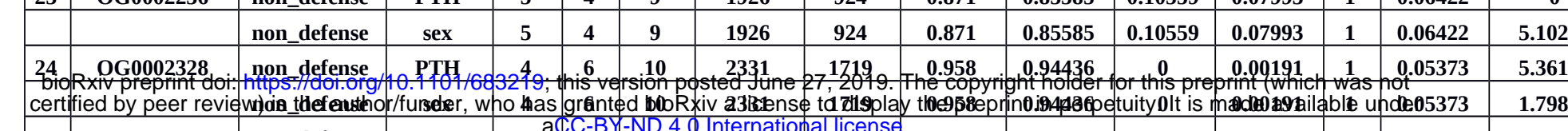

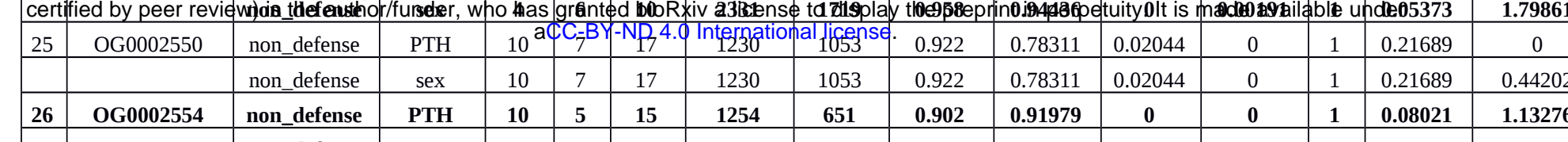

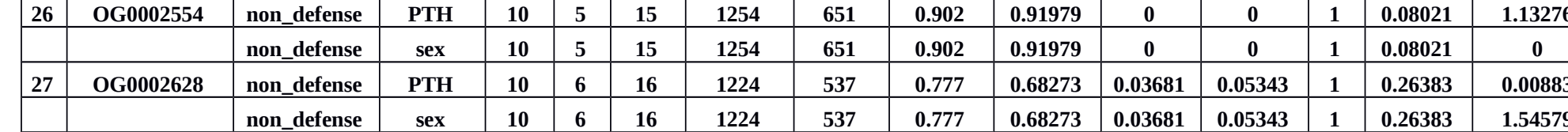

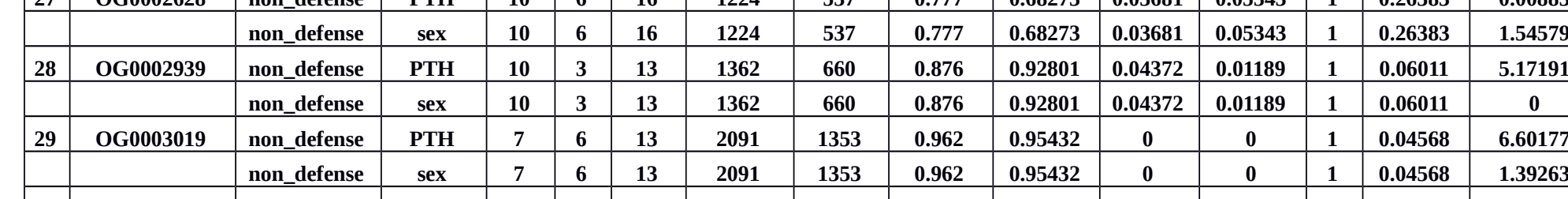

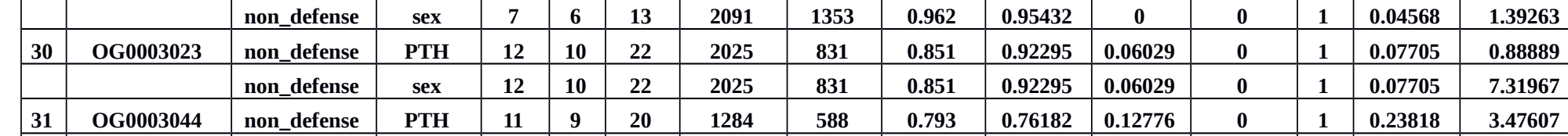

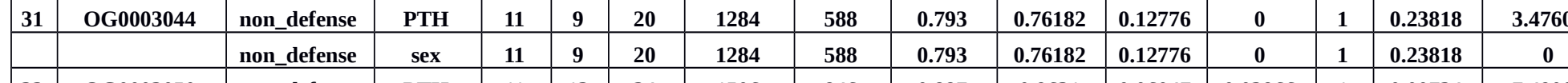

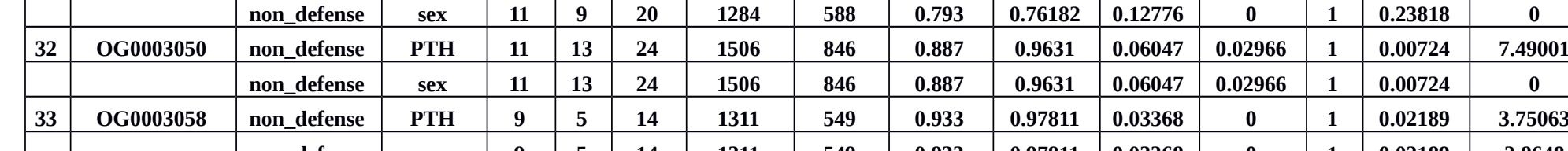

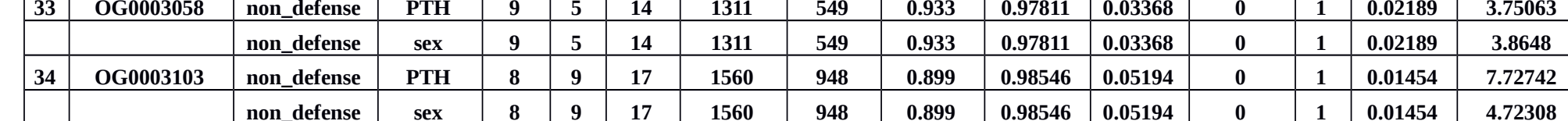

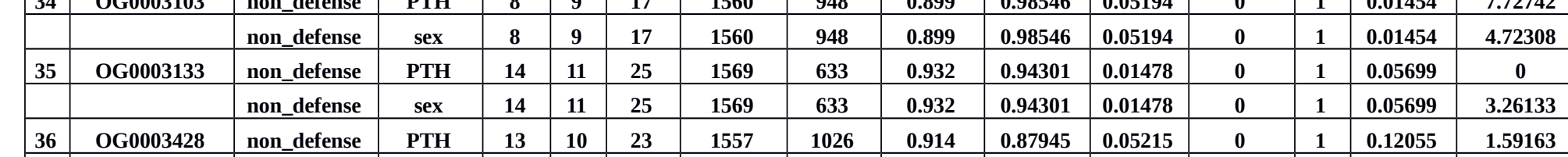

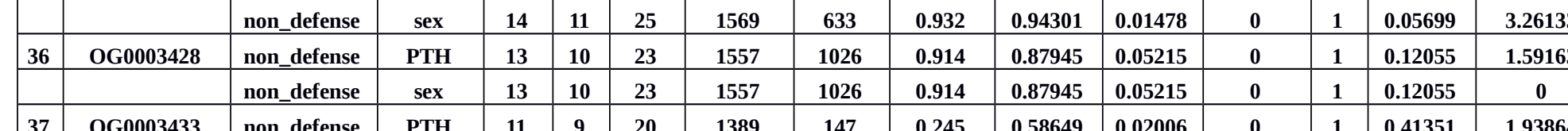

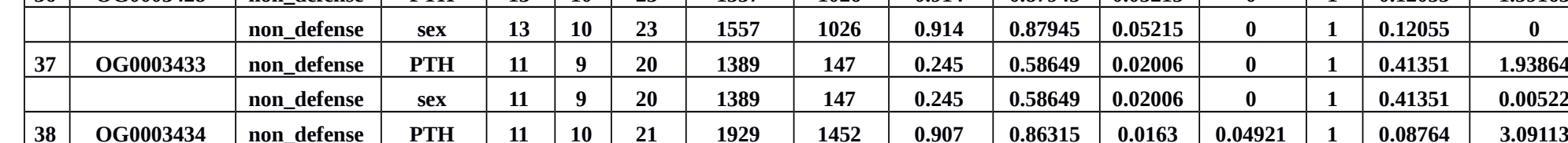

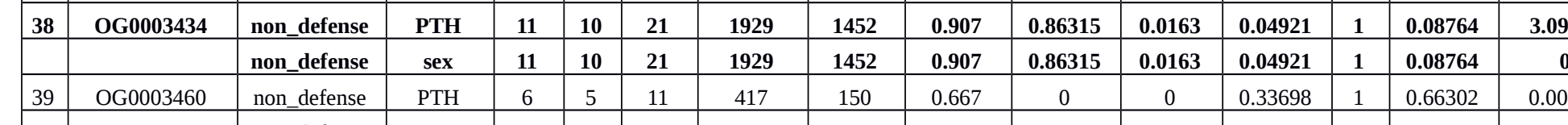

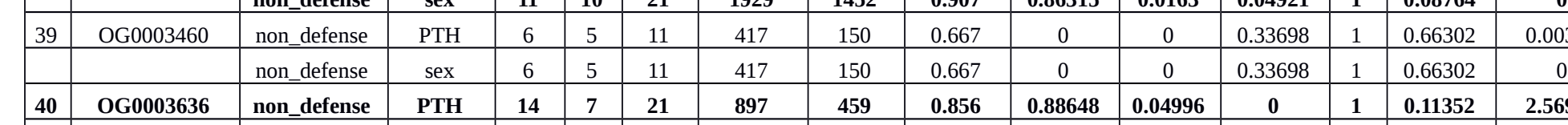

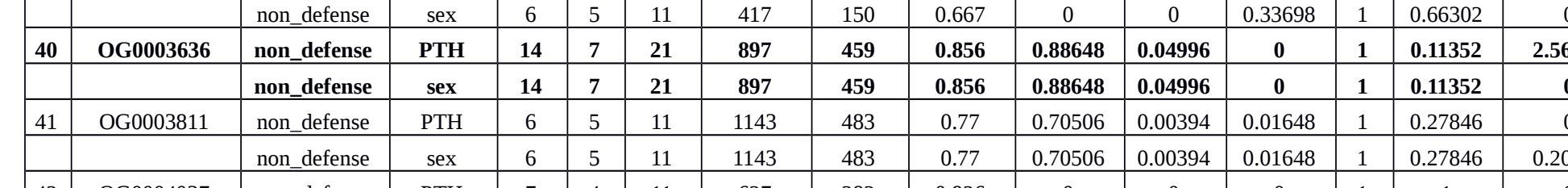

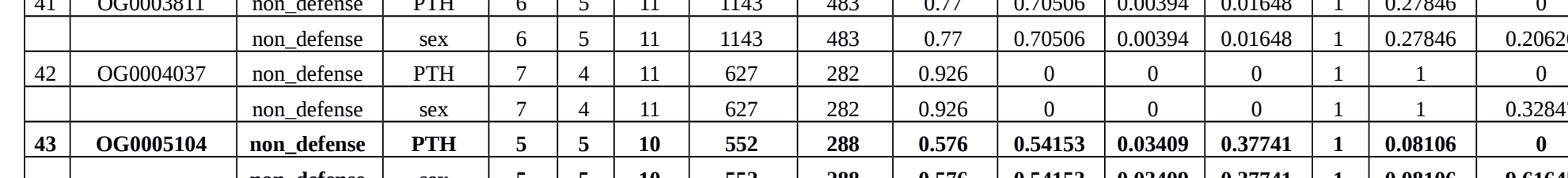

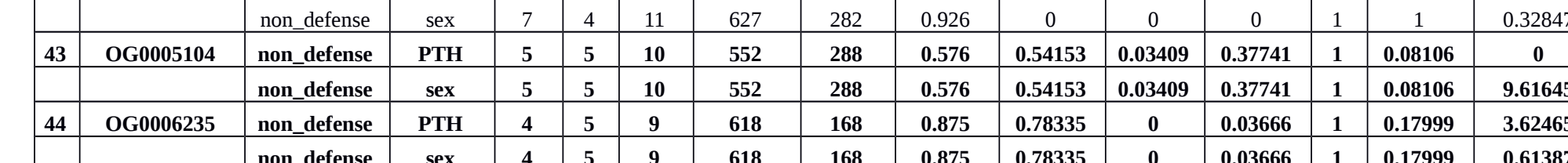

\begin{tabular}{|c|c|c|c|}
\hline Qqu⿰wo & A A38292400 & Lox5 & |Linoleat___5S-ipoxygenase_.5 \\
\hline O97812 & ${ }_{A 4503190}$ & GRH1 & GRRI-like_protetin_1 \\
\hline Q39027 & AAR218170 & MPK7 & Mitiogen-activated__rottin_kinase_7 \\
\hline Q92VDS & Al2p277040 & 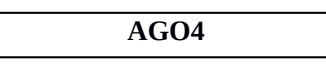 & Protein_argonaute_4 \\
\hline Q8ะLDo & At1980680 & NUP96 & Nuclear _pore complex protetin_NUP96 \\
\hline 0987091.065399 & At2g01630_Attg11820 & At2g01630/At191820 & 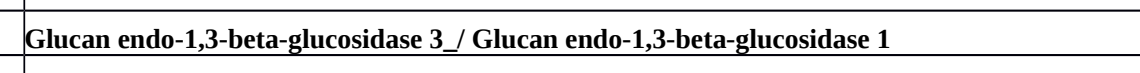 \\
\hline Q95SUQ_egrPQ3 & At4529810_At1918350 & MKK2/MKK & 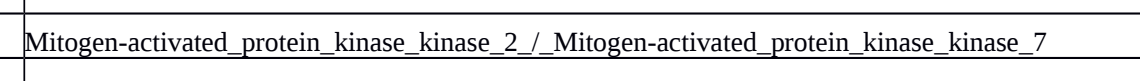 \\
\hline Q982ZA7 & A4tag33300 & 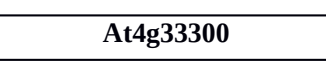 & 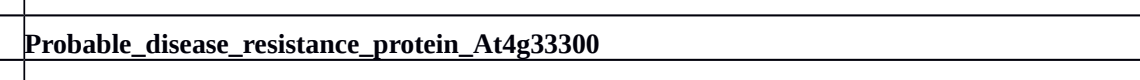 \\
\hline Q96509 & At1965390 & PP2A5 & protein. PHLOEM.PROTEN 2-LIKE.AS \\
\hline Q9LPU7 & Allg21120 & IGMI2 & 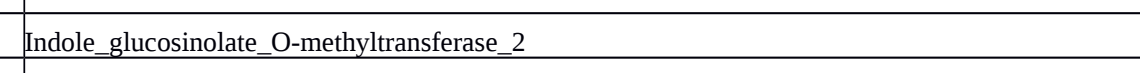 \\
\hline Q9LuB9 & At5g48130 & Al55484130 & BTBPOZ_domain-containing protetin \\
\hline P99990 & At1g70370 & PGL3 & Polygalacturonase__bectatike provetin_3 3 \\
\hline QgZVF2 & At2801530 & MLP329 & MLP-like protein_329 \\
\hline Q9LFP5 & At591510 & A5651510 & 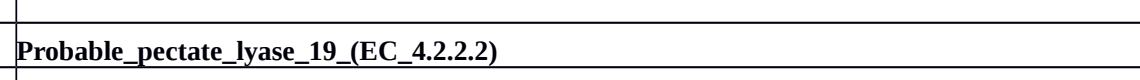 \\
\hline Q99KU___9927T4 & 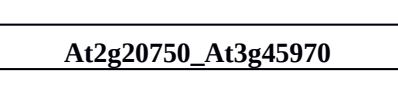 & EXPB1/EXLA1 & Expansin-B1_Expansin-ilike_A1 \\
\hline Q9Fira & At5599930 & $\mathrm{ABCF2}$ & ABC__ransporter___family_member_2 2 \\
\hline Q44883 & A A5514930 & SAG101 & 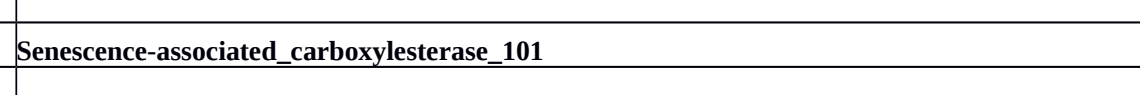 \\
\hline Q6E 198 & At4937610 & BT5 & BTBPOZ_an__IAZ__domain-contanining_protetin_5. \\
\hline Q99EZ9__99Y46__9FG35 & 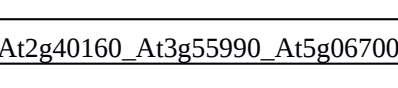 & TBBL30/ESK1/TBR & 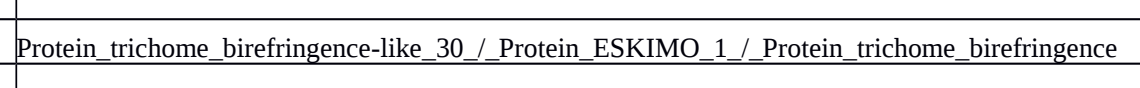 \\
\hline Q996H2_-884434 & Al166630_AL5837930 & Atl1566630/A15837930 & 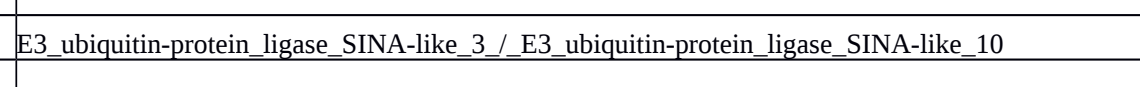 \\
\hline Q99095 & Al2336990 & SIGF & RNA_polymerase__igma factor_sigF \\
\hline Q99c9p4 & All187960 & KAS2 & 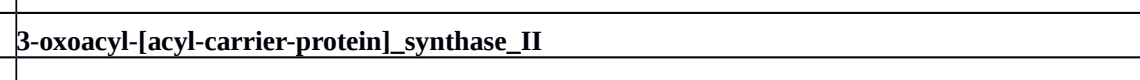 \\
\hline Q94FD1 & At5g01050 & LAC9 & Laccase-9 \\
\hline Q99537 & At3899660 & мсм8 & Probable._DA helicise_.MCMB \\
\hline Q9CA63 & Allg 4510 & At1874510 & F-boxkelch-repeat_protein \\
\hline Q95A14 & Al180760 & NIPG-1 & Aquaporin_NIP6-1 \\
\hline Q9MQY5__Q95IF3 & 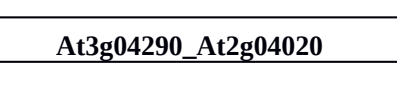 & 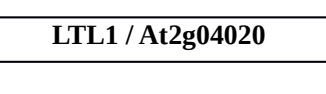 & GDSL_esteraselipase_LITL__CDSL_esteraselipase \\
\hline Q94075_9920256 & At5559550_AzBg55530 & DURF/ SDIR1 & 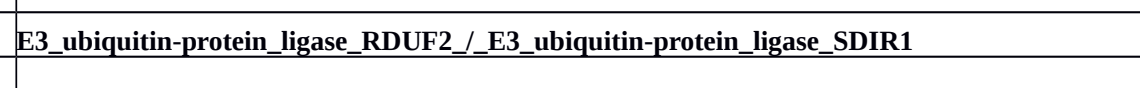 \\
\hline Q995T1 & At83847820 & PUB39 & U.-box_domain-containing proteiei__39 \\
\hline Q8vZ79 & At3848670 & $\mathrm{IDN}^{2}$ & Protetin INVOLVED_IN DE NONOO_.2 \\
\hline Q95834 & At1902560 & CLPP5 & 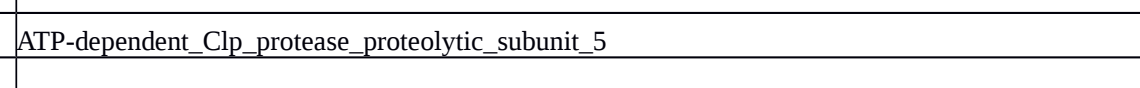 \\
\hline Q98P16 & $\mathrm{Al}_{482} 3190$ & CRKII & 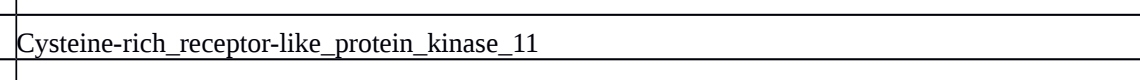 \\
\hline 065683 & At4433550 & BZPIII & bzIP _tanscripion factor-11 \\
\hline Q92540 & ABg18490 & ASPG1 & Protein_ASPARTIC,PROTEASE_IN_GUARD_CELL_1 \\
\hline Q9MA75 & All1933700 & VIP1 & Transcripition_factor_VIP1 \\
\hline Q995TM4 & A 13584440 & ABg848440 & 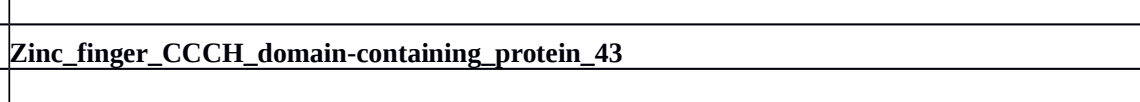 \\
\hline Q99XB6 & All156670 & LIP4 & GDSL_esterasellipase_LIP.4 \\
\hline Q92ZA3 & Al2801750 & MAP 0.3 & Microutbule-associated protein_70.3 \\
\hline FulCN9 & AB8 847710 & PREA & Transcripioion_factor P PRE4 \\
\hline Q9LUL6__osRRMo & ABg814320_ABg811110 & ATL61/ATL66 & 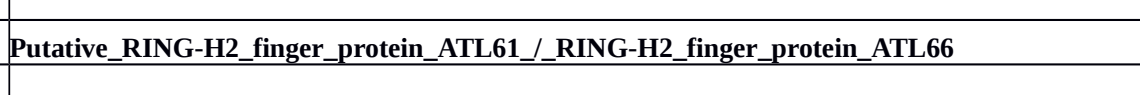 \\
\hline Q9PQP3 & Al1918350 & MKK 7 & 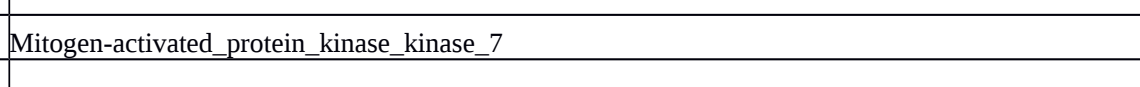 \\
\hline Q9c9p4 & Antg 4960 & KAS2 & 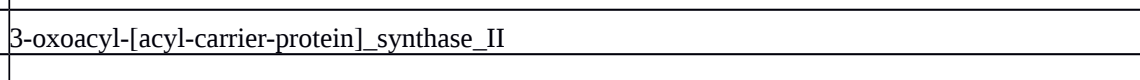 \\
\hline Q88RX83 & At2932530 & CSLB3 & Cellulose_synthase-ike__protein_B3 \\
\hline Q98XIN__Q9ZVHO & At2827300_Al1926870 & $\mathrm{NTLB/FEZ}$ & NaC_domanin-contanining prottin_40__Protetin_EEZ \\
\hline
\end{tabular}


1210 Table S3. GO enrichment test using genes under positive selection detected by branch-site models in PAML. See fig. S3 for a graphical representation of this result, and fig. S4 to

1212 visualize the position of the first statistically significant GO terms (in bold) in the GO hierarchy.

1213 TopGo was used to perform these analyses using the default algorithm and a Fisher exact

1214 test (Alexa et al. 2006). Only terms with a $P$-value $<0.05$. are shown.

1215

\section{GO ID}

GO:0051301

GO:0007049

GO:0051607

GO:0080119

GO:0006491

GO:0009911

GO:0000165

GO:0009585

GO:0009610

GO:0010114

GO:0010218

GO:2000031

GO:0009788

GO:0042344

GO:0070417
Term

cell division

cell cycle

defense response to virus

ER body organization

$\mathbf{N}$-glycan processing

positive regulation of flower

development

MAPK cascade

red, far-red light phototransduction

response to symbiotic fungus

response to red light

response to far red light

regulation of salicylic acid mediated signaling pathway negative regulation of abscisic acidactivated signaling pathway

indole glucosinolate catabolic process

cellular response to cold

\begin{tabular}{rrrr} 
Annotated & Enriched & \multicolumn{2}{c}{ Expected } \\
11 & $\mathbf{2}$ & $\mathbf{0 . 3 1}$ & $\mathbf{0 . 0 0 2}$ \\
$\mathbf{1 2}$ & $\mathbf{2}$ & $\mathbf{0 . 3 4}$ & $\mathbf{0 . 0 0 2 4}$ \\
$\mathbf{1 5}$ & $\mathbf{2}$ & $\mathbf{0 . 4 2}$ & $\mathbf{0 . 0 0 3 8}$ \\
$\mathbf{1}$ & $\mathbf{1}$ & $\mathbf{0 . 0 3}$ & $\mathbf{0 . 0 0 6 7}$ \\
$\mathbf{1}$ & $\mathbf{1}$ & $\mathbf{0 . 0 3}$ & $\mathbf{0 . 0 0 6 7}$ \\
& & & \\
2 & 1 & 0.06 & 0.0134 \\
2 & 1 & 0.06 & 0.0134 \\
2 & 1 & 0.06 & 0.0134 \\
2 & 1 & 0.06 & 0.0134 \\
3 & 1 & 0.08 & 0.0201 \\
3 & 1 & 0.08 & 0.0201 \\
& & & \\
3 & 1 & 0.08 & 0.0201 \\
& & & \\
3 & 1 & 0.08 & 0.0201 \\
3 & 1 & 0.08 & 0.0201 \\
5 & 1 & 0.14 & 0.0333
\end{tabular}


1229 Table S4. GO enrichment test using genes under divergent evolution detected by Clade 1230 models in PAML. See fig. S5 for a graphical representation of this result, and fig. S6 to 1231 visualize the position of the first five statistically significant GO terms (in bold) in the GO 1232 hierarchy. TopGo was used to perform these analyses using the default algorithm and a 1233 Fisher exact test (Alexa et al. 2006). Only terms with a $P$-value $<0.05$. are shown.

\begin{tabular}{|c|c|c|c|c|c|}
\hline GO.ID & Term & Annotated Enriched & & Expected & $P$-value \\
\hline GO:0006952 & $\begin{array}{l}\text { defense response } \\
\text { stress-activated protein kinase signaling }\end{array}$ & 305 & 10 & 14.39 & 0.00071 \\
\hline GO:0031098 & cascade & 4 & 2 & 0.19 & 0.00082 \\
\hline GO:0007346 & $\begin{array}{l}\text { regulation of mitotic cell cycle } \\
\text { posttranscriptional tethering of RNA } \\
\text { polymerase II gene DNA at nuclear }\end{array}$ & 6 & 2 & 0.28 & 0.00203 \\
\hline GO:0000973 & $\begin{array}{l}\text { periphery } \\
\text { negative regulation of defense response to }\end{array}$ & 1 & 1 & 0.05 & 0.01236 \\
\hline GO:1900366 & $\begin{array}{l}\text { insect } \\
\text { modulation by virus of host morphology or }\end{array}$ & 1 & 1 & 0.05 & 0.01236 \\
\hline GO:0019048 & physiology & 1 & 1 & 0.05 & 0.01236 \\
\hline GO:0034398 & telomere tethering at nuclear periphery & 1 & 1 & 0.05 & 0.01236 \\
\hline GO:0009926 & auxin polar transport & 1 & 1 & 0.05 & 0.01236 \\
\hline GO:0045014 & $\begin{array}{l}\text { negative regulation of transcription by glucose } \\
\text { production of siRNA involved in chromatin }\end{array}$ & 1 & 1 & 0.05 & 0.01236 \\
\hline GO:0070919 & silencing by small RNA & 1 & 1 & 0.05 & 0.01236 \\
\hline GO:0009631 & cold acclimation & 2 & 1 & 0.09 & 0.02458 \\
\hline GO:0006606 & protein import into nucleus & 2 & 1 & 0.09 & 0.02458 \\
\hline GO:0010152 & $\begin{array}{l}\text { pollen maturation } \\
\text { production of siRNA involved in RNA }\end{array}$ & 2 & 1 & 0.09 & 0.02458 \\
\hline GO:0030422 & interference & 2 & 1 & 0.09 & 0.02458 \\
\hline GO:0080188 & RNA-directed DNA methylation & 2 & 1 & 0.09 & 0.02458 \\
\hline GO:0051567 & histone H3-K9 methylation & 2 & 1 & 0.09 & 0.02458 \\
\hline GO:0010311 & lateral root formation & 2 & 1 & 0.09 & 0.02458 \\
\hline GO:0010051 & xylem and phloem pattern formation & 2 & 1 & 0.09 & 0.02458 \\
\hline GO:0010468 & regulation of gene expression & 55 & 3 & 2.6 & 0.03191 \\
\hline GO:0060918 & $\begin{array}{l}\text { auxin transport } \\
\text { defense response signaling pathway, resistance }\end{array}$ & 4 & 2 & 0.19 & 0.0334 \\
\hline GO:0009870 & gene-dependent & 3 & 1 & 0.14 & 0.03666 \\
\hline GO:0031408 & oxylipin biosynthetic process & 3 & 1 & 0.14 & 0.03666 \\
\hline GO:0042542 & response to hydrogen peroxide & 3 & 1 & 0.14 & 0.03666 \\
\hline GO:0051028 & $\begin{array}{l}\text { mRNA transport } \\
\text { systemic acquired resistance, salicylic acid }\end{array}$ & 3 & 1 & 0.14 & 0.03666 \\
\hline GO:0009862 & mediated signaling pathway & 3 & 1 & 0.14 & 0.03666 \\
\hline GO:0034440 & lipid oxidation & 3 & 1 & 0.14 & 0.03666 \\
\hline
\end{tabular}




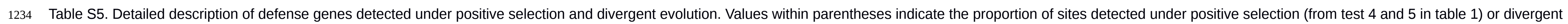
1235 evolution (from test 6 in table 1). Table S2 shows the full set of genes under positive selection and divergent evolution.

\begin{tabular}{|c|c|c|c|c|c|}
\hline Gene name & Protein Name & $\begin{array}{l}\text { Magnitude of positive } \\
\text { selection }\end{array}$ & Broad function & Detailed function & Citation \\
\hline \multicolumn{6}{|c|}{ Positive selection based on branch-site model } \\
\hline PSL4 & Glucosidase 2 subunit beta & SEX: $\omega_{2=1}(p=0.226)$ & Mediates pathogen detection & $\begin{array}{l}\text { It is essential for stable accumulation of the receptor EFR that determines the specific } \\
\text { perception of bacterial elongation factor. }\end{array}$ & Lu et al. (2009) \\
\hline EDR1 & $\begin{array}{l}\text { Serine/threonine-protein } \\
\text { kinase EDR1 }\end{array}$ & PTH: $\omega_{2}=1(p=0.0)$ & $\begin{array}{l}\text { Mediates signalling for induced } \\
\text { responses }\end{array}$ & $\begin{array}{l}\text { It encodes a putative mitogen-activated protein kinase kinase kinase (MAPKKK) and } \\
\text { mediates resistance based on salicylic acid (SA)-inducible defenses. }\end{array}$ & Frye et al. (2001) \\
\hline BGLU23 & Beta-glucosidase 23 & PTH: $\omega_{2}=8.308(p=0.081)$ & $\begin{array}{l}\text { Mediates expression of induced } \\
\text { response }\end{array}$ & $\begin{array}{l}\text { A glucosidase associated with the methyl jasmonate-induced endoplasmic reticulum } \\
\text { bodies in the roots, which hydrolyzes scopolin. }\end{array}$ & $\begin{array}{l}\text { Ahn et al. (2010) } \\
\text { Sherameti et al. } \\
\text { (2008) }\end{array}$ \\
\hline $\begin{array}{l}\text { ARLBC/ } \\
\text { ARLBA }\end{array}$ & $\begin{array}{l}\text { ADP-ribosylation factor-like } \\
\text { protein 8a / ADP- } \\
\text { ribosylation factor-like } \\
\text { protein 8a }\end{array}$ & SEX: $\omega_{2}=6.225(p=0.662)$ & $\begin{array}{l}\text { Inhibits virus infection (RNA } \\
\text { silencing-based defenses) }\end{array}$ & $\begin{array}{l}\text { The lack of these proteins completely inhibited tobamovirus multiplication by inhibited the } \\
\text { production of replicative-form RNA. }\end{array}$ & Nishikiori et al. (2011) \\
\hline MED25 & $\begin{array}{l}\text { Mediator of RNA } \\
\text { polymerase II transcription } \\
\text { subunit } 25\end{array}$ & PTH: $\omega_{2}=2.726(p=0.927)$ & Mediates induce defense & $\begin{array}{l}\text { it is known to play a defensive role mediating the expression of jasmonate-dependent } \\
\text { defenses and resistance against necrotrophic fungal pathogens. }\end{array}$ & Kidd et al. (2009) \\
\hline \multicolumn{6}{|c|}{ Divergent evolution } \\
\hline NUP96 & $\begin{array}{l}\text { Nuclear pore complex } \\
\text { protein NUP96 }\end{array}$ & $\begin{array}{l}\omega_{\mathrm{SEX}}=1.892 \\
\omega_{\mathrm{PTH}}=0 \\
(p=0.127)\end{array}$ & $\begin{array}{l}\text { Mediates the expression of R- } \\
\text { genes }\end{array}$ & $\begin{array}{l}\text { Suppression of this gene reduce constitutive and basal (i.e., innate immunity also called } \\
\text { nonhost resistance) defense since it encodes for a nucleoporin protein involved in nuclear } \\
\text { mRNA exportation that mediates the expression of R-gene such as snct and RPP4, } \\
\text { RPMM1, RPS4, which are pathogenesis-related (PR) genes involved in the susceptibility to } \\
\text { bacteria and fungi, but is also implicated in plant response to symbiotic microbes }\end{array}$ & $\begin{array}{l}\text { Zhang (2005) } \\
\text { Wiermer et al. (2012) }\end{array}$ \\
\hline$\angle O X 5$ & Linoleate 9S-lipoxygenase 5 & $\begin{array}{l}\omega_{\mathrm{SEXX}}=6.162 \\
\omega_{\text {PTH }}=0 \\
(p=0.049)\end{array}$ & $\begin{array}{l}\text { Putative mediator of induced } \\
\text { defense }\end{array}$ & $\begin{array}{l}\text { Lipoxygenases (LOX) are involved in the first step in the biosynthesis of oxylipins such as } \\
\text { jasmonic acid, which affect plant physiology, growth root development, senescence, and } \\
\text { pest resistance. There is no clear experimental evidence to support that LOX5 is directly } \\
\text { involved in defense as detected for LOX9 (Velllosillo et all. 2007). Actually, based on protein } \\
\text { similarity analyses, attoX5 (A. thaliana LOX5) it is out of the phylogenetic cluster of LOXs } \\
\text { proteins related with defensive pathways (Bannenberg et al. 2009) }\end{array}$ & $\begin{array}{l}\text { Vellosillo et al. (2007) } \\
\text { Bannenberg et al. } \\
\text { (2009) }\end{array}$ \\
\hline GRH1 & GRR1-like protein 1 & $\begin{array}{l}\omega_{\mathrm{SEX}}=0.084 \\
\omega_{\mathrm{PTH}}=0 \\
(p=0.903)\end{array}$ & Mediates detection & Confers sensitivity to the virulent bacterial pathogen & Navarro et al. (2006) \\
\hline MPK7 & $\begin{array}{l}\text { Mitogen-activated protein } \\
\text { kinase } 7\end{array}$ & $\begin{array}{l}\text { S } \\
\omega_{\text {SEX }}=0 \\
(p=5.857 \\
(p=0.049)\end{array}$ & $\begin{array}{l}\text { Mediates signaling for induced } \\
\text { defense }\end{array}$ & $\begin{array}{l}\text { It is triggered by a signal produced in plants after pathogen recognition events }\left(\mathrm{H}_{2} \mathrm{O}_{2}\right) \text {, and } \\
\text { together with the MKK3 kinase co-regulates the expression of the PR ProPRR:GUS }\end{array}$ & Dóczi et al. (2007) \\
\hline AGO4 & Protein argonaute 4 & $\begin{array}{l}\omega_{\text {SEXX }}=0.123 \\
\omega_{P T H}=2.865 \\
(p=0.236)\end{array}$ & Mediates constitutive defense & $\begin{array}{l}\text { A key protein that loads small RNAs (SRNAs) to induce DNA methylation (RNA-directed } \\
\text { DNA methylation; RdDM) and histone modifications that modulate the host immune } \\
\text { system affecting the expression of the GUS gene that codes for a } \beta \text {-glucuronidase. }\end{array}$ & $\begin{array}{l}\text { Agorio and Vera } \\
\text { (2007) }\end{array}$ \\
\hline 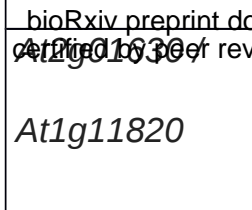 & 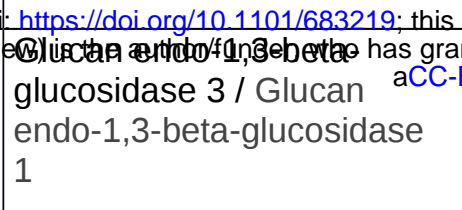 & 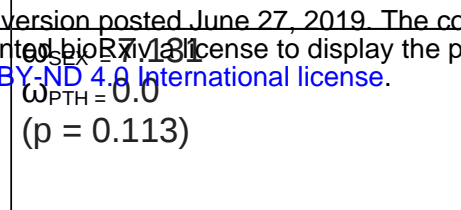 & 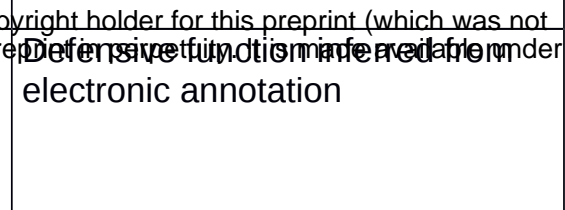 & Defensive function inferred from electronic annotation & $\begin{array}{l}\text { Uniprot } \\
\text { https://goo.gl/4AiVmy }\end{array}$ \\
\hline MKK2 / MKK7 & $\begin{array}{l}\text { Mitogen-activated protein } \\
\text { kinase kinase } 2 \text { / Mitogen- } \\
\text { activated protein kinase } \\
\text { kinase } 7\end{array}$ & $\begin{array}{l}\omega_{\text {SEX }}=0.256 \\
\omega_{\text {PTH }}=0 \\
(p=0.288)\end{array}$ & $\begin{array}{l}\text { Mediates constitutive and induced } \\
\text { defense }\end{array}$ & $\begin{array}{l}\text { Increase level of salicylic acid and the expression of PR genes enhancing plant basal and } \\
\text { systemic acquired resistance }\end{array}$ & $\begin{array}{l}\text { Zhang et al. (2007) } \\
\text { Gao et al. (2008) }\end{array}$ \\
\hline At4933300 & $\begin{array}{l}\text { Probable disease resistance } \\
\text { protein At4g33300 }\end{array}$ & $\begin{array}{l}\omega_{\text {SEX }}=9.697 \\
\omega_{\text {PTH }}=0.812 \\
(p=0.152)\end{array}$ & $\begin{array}{l}\text { Defensive function inferred from } \\
\text { sequence similarity }\end{array}$ & Defensive function inferred from sequence similarity & $\begin{array}{l}\text { Uniprot } \\
\text { https://goo.gl/sDaWfu }\end{array}$ \\
\hline PP2A5 & $\begin{array}{l}\text { Serine/threonine-protein } \\
\text { phosphatase PP2A-5 } \\
\text { catalytic subunit }\end{array}$ & $\begin{array}{l}\omega_{\mathrm{SEXX}}=0 \\
\omega_{\mathrm{PTH}}=2.016 \\
(p=0.539)\end{array}$ & $\begin{array}{l}\text { Detection and mediator of } \\
\text { defensive response }\end{array}$ & Promoters inducible by flagellin 22 peptide & $\begin{array}{l}\text { Czarnecka et al. } \\
\text { (2012) }\end{array}$ \\
\hline
\end{tabular}




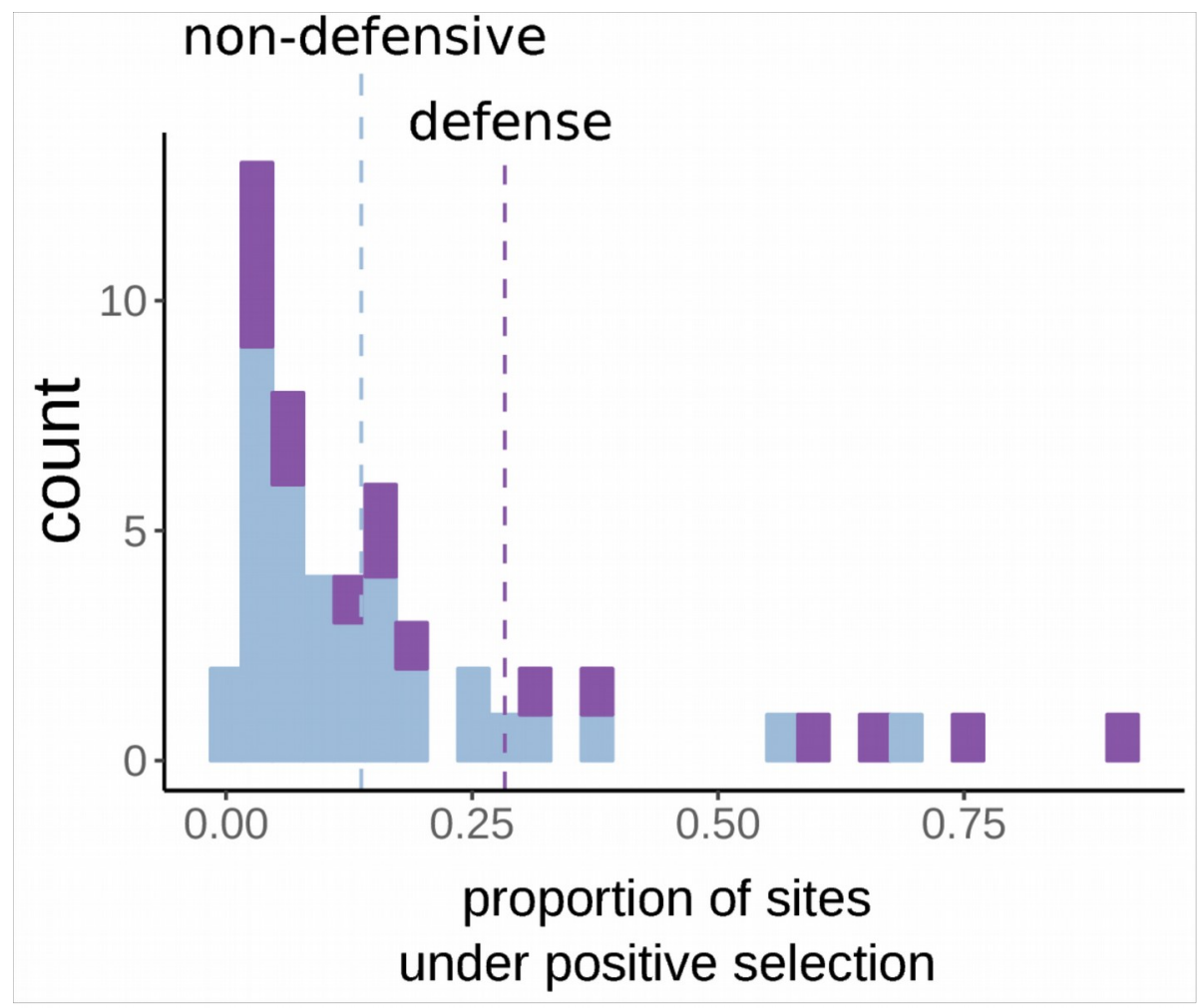

1237 FIG. S1. Proportion of amino acid sites experiencing positive selection in defense and nondefensive genes. 


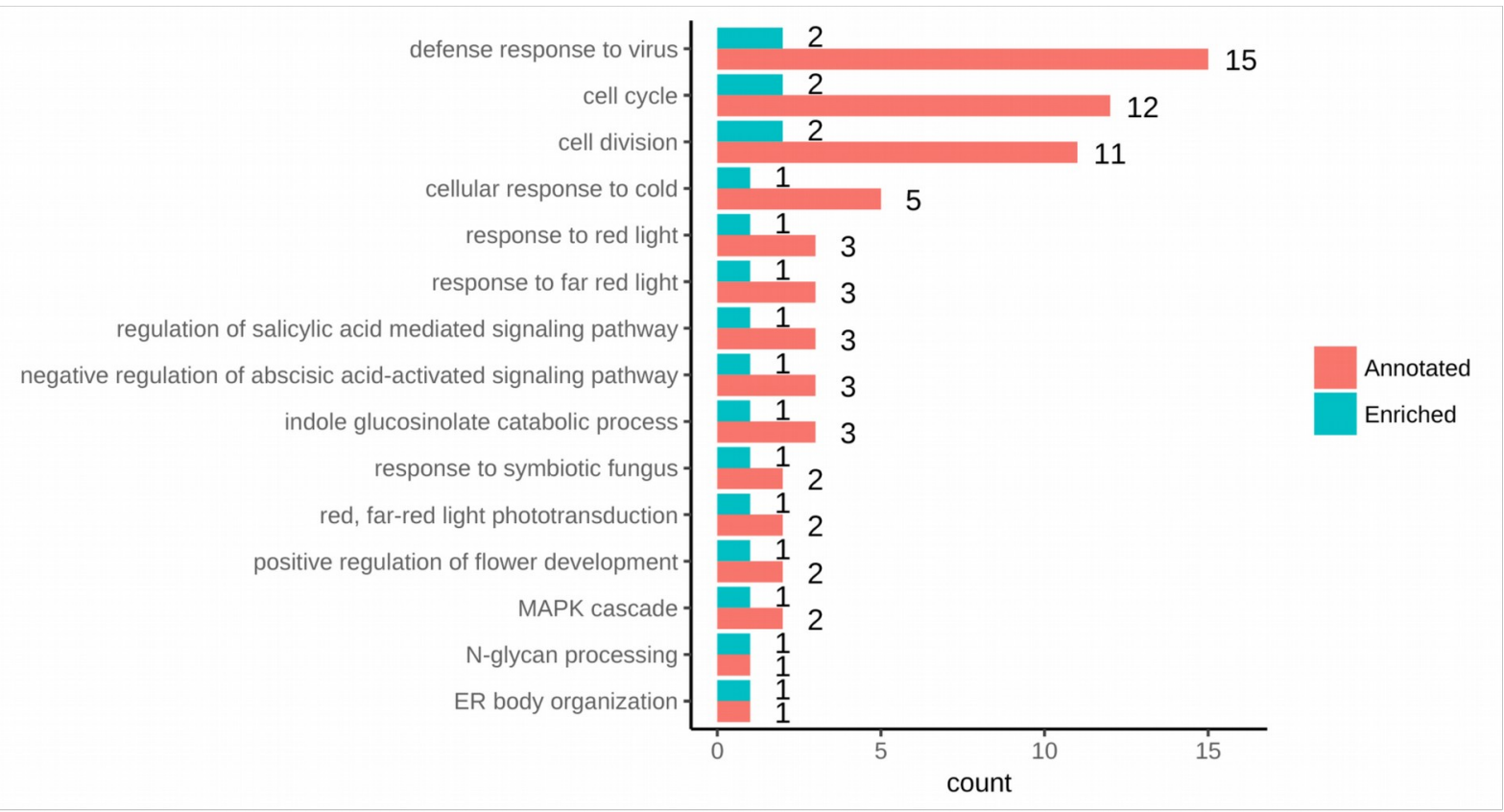

1257

1258

1259 FIG. S2. Graphical representation of enrichment analysis for defensive genes under positive 


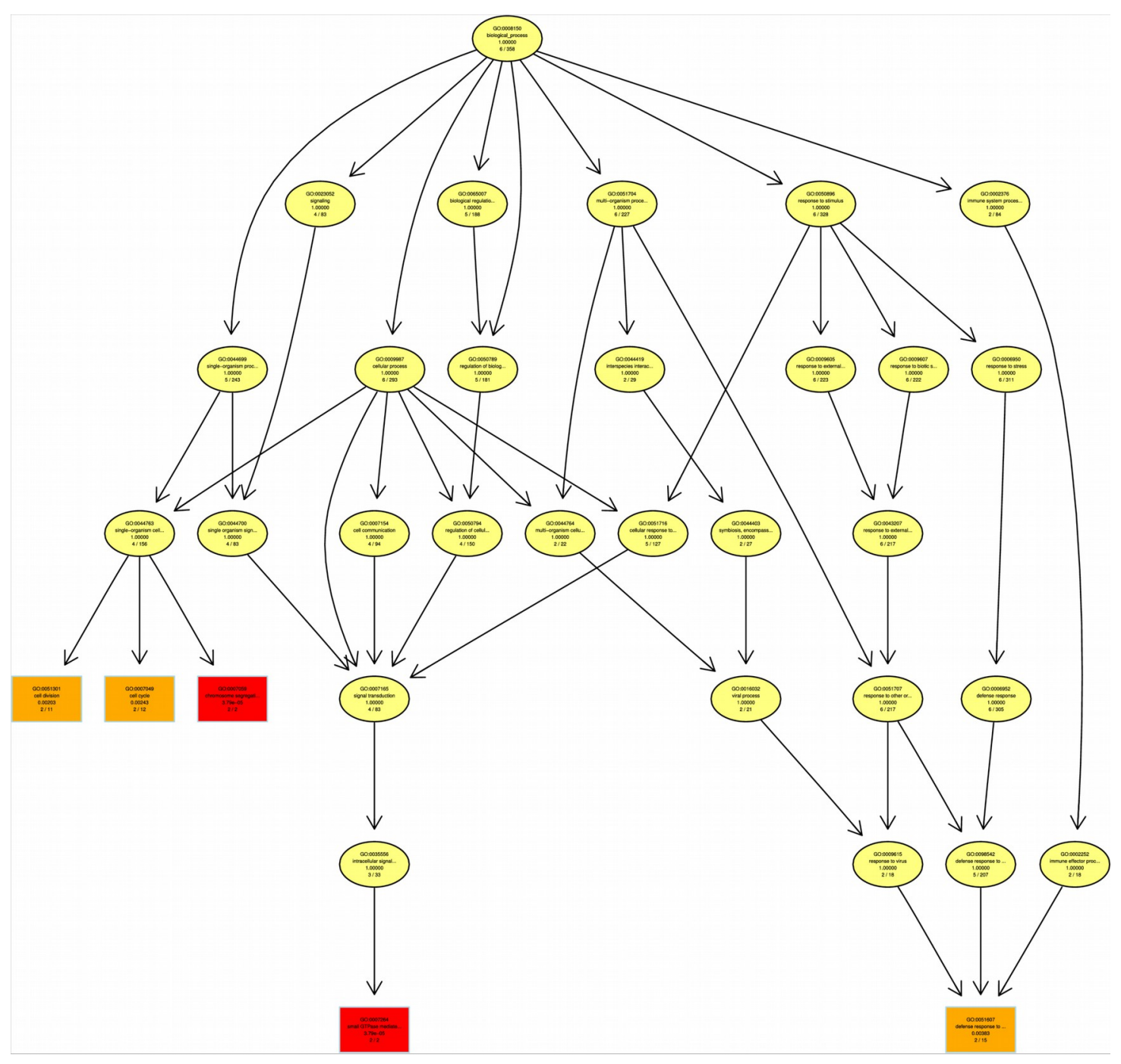

FIG. S3. GO structure for the first five enriched nodes detected by the enrichment test. Terms framed within a rectangle are significant and an increase in red coloration indicates higher values of significance (i.e., lower $P$-values) in the enriched test. Zoom in to see the identity and additional information about the nodes. . 


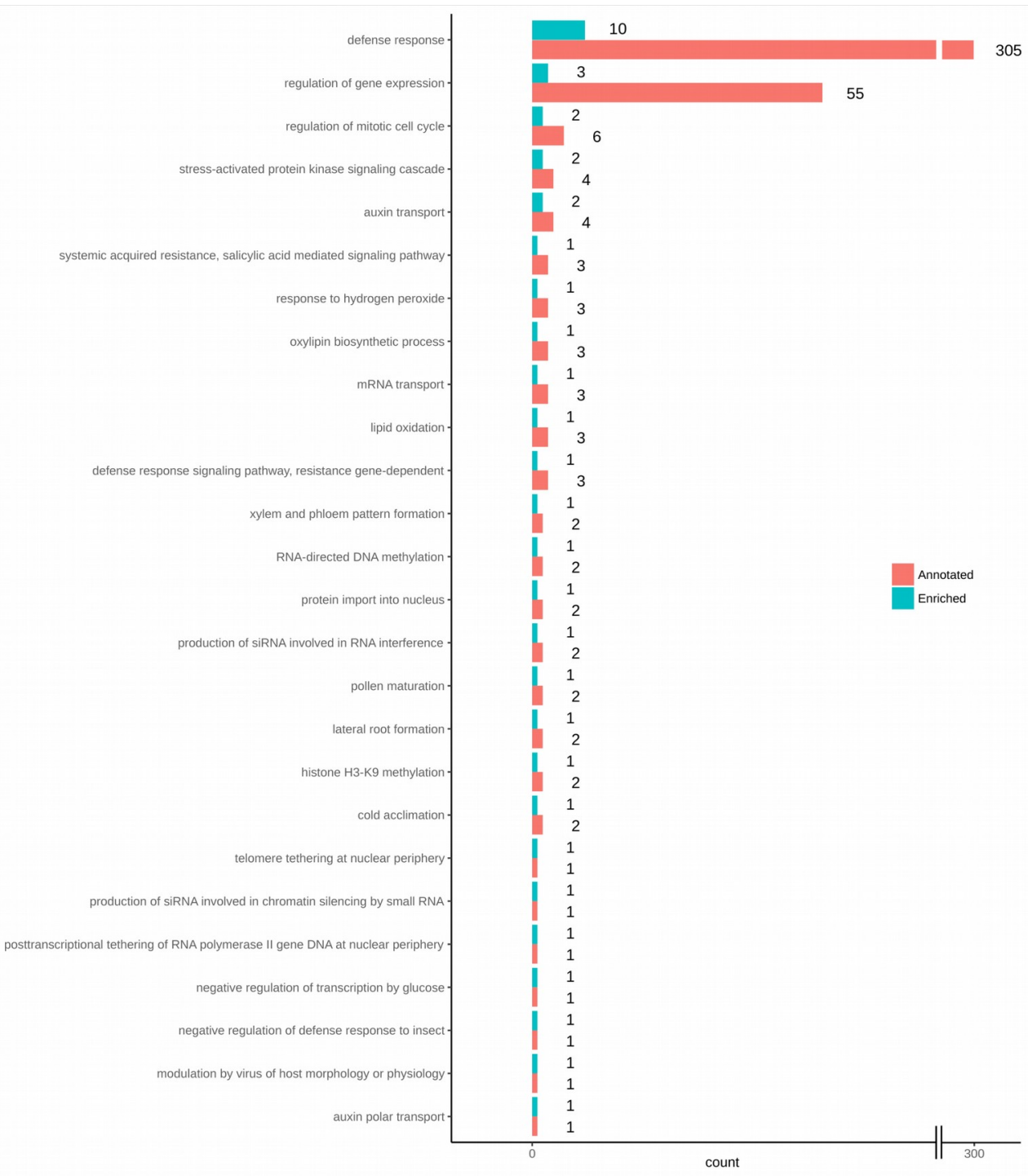

FIG. S4. Graphical representation of enrichment analysis for defensive genes under divergent evolution detected by clade models. 
FIG. S5. GO structure for the first five enriched nodes detected by the enrichment test of genes under divergent evolution. Terms framed within a rectangle are significant and an increase in red coloration indicates higher values of significance (i.e., lower $P$-values) in the enriched test. Zoom in to see the identity and additional information about the nodes. 